\title{
Clinically Relevant Interactions between Atypical Antipsychotics and Anti-Infective Agents
}

\author{
Edoardo Spina ${ }^{1, *(\mathbb{D}}$, Maria Antonietta Barbieri ${ }^{1}{ }^{(\mathbb{C}}$, Giuseppe Cicala $^{1}(\mathbb{D})$ and Jose de Leon ${ }^{2,3,4}$ \\ 1 Department of Clinical and Experimental Medicine, University of Messina, 98125 Messina, Italy; \\ mbarbieri@unime.it (M.A.B.); gcicala@unime.it (G.C.) \\ 2 Mental Health Research Center at Eastern State Hospital, University of Kentucky, Lexington, KY 40511-1269, \\ USA; jdeleon@uky.edu \\ 3 Psychiatry and Neurosciences Research Group (CTS-549), Institute of Neurosciences, University of Granada, \\ 18011 Granada, Spain \\ 4 Biomedical Research Centre in Mental Health Net (CIBERSAM), Santiago Apostol Hospital, University of \\ the Basque Country, 01004 Vitoria, Spain \\ * Correspondence: espina@unime.it; Tel.: +39-090-221-3650
}

Received: 5 October 2020; Accepted: 30 November 2020; Published: 2 December 2020

\begin{abstract}
This is a comprehensive review of the literature on drug interactions (DIs) between atypical antipsychotics and anti-infective agents that focuses on those DIs with the potential to be clinically relevant and classifies them as pharmacokinetic (PK) or pharmacodynamic (PD) DIs. PubMed searches were conducted for each of the atypical antipsychotics and most commonly used anti-infective agents (13 atypical antipsychotics by 61 anti-infective agents/classes leading to 793 individual searches). Additional relevant articles were obtained from citations and from prior review articles written by the authors. Based on prior DI articles and our current understanding of PK and PD mechanism, we developed tables with practical recommendations for clinicians for: antibiotic DIs, antitubercular DIs, antifungal DIs, antiviral DIs, and other anti-infective DIs. Another table reflects that in clinical practice, DIs between atypical antipsychotics and anti-infective agents occur in patients also suffering an infection that may also influence the PK and PD mechanisms of both drugs (the atypical antipsychotic and the anti-infective agent(s)). These tables reflect the currently available literature and our current knowledge of the field and will need to be updated as new DI information becomes available.
\end{abstract}

Keywords: antipsychotic agents; antibacterial agents; antibiotics; antitubercular; antifungal agents; antimalarials; antiviral agents; drug interactions; pharmacology; pharmacokinetics

\section{Introduction}

Drug combinations are increasingly used in the treatment of many conditions and represent an important risk factor for the occurrence of drug interactions (DIs) [1]. A clinically relevant DI occurs when the efficacy or safety of a drug is altered by the concomitant administration of another medication. In a few cases, DIs may prove beneficial, resulting in an increased efficacy or reduced risk of adverse drug reactions (ADRs), and therefore certain drug combinations may be used advantageously in clinical practice. However, more often, DIs are harmful, leading to diminished efficacy or increased toxicity of one or more of the administered medications.

Currently available antipsychotic drugs can be divided into typical or first-generation antipsychotics and atypical or second-generation antipsychotics. In recent years, atypical antipsychotics (amisulpride, aripiprazole, asenapine, brexipiprazole, cariprazine, clozapine, iloperidone, lurasidone, olanzapine, paliperidone, quetiapine, risperidone, and ziprasidone) have progressively replaced 
older, typical agents due to better safety profiles for reversible extrapyramidal symptoms and tardive dyskinesia [2]. Moreover, new antipsychotics are increasingly prescribed not only for schizophrenia and bipolar disorder, but also for other psychiatric conditions such as adjuvant treatment of major depressive disorder, psychosis and behavioral disorders in dementia, psychosis associated with Parkinson's disease, resistant obsessive-compulsive disorder, aggressive behavior, and irritability in autism spectrum disorders [2]. Over the past few years, a number of reviews have described the clinically relevant DIs between atypical antipsychotics and various CNS medications including antiepileptics [3] and antidepressants [4].

Anti-infective agents are medications capable of preventing or treating infections. They include a number of widely used classes of drugs such as antibiotics, antituberculosis agents, antifungals, anthelmintics, antimalarials, and antivirals. Many anti-infective medications can lead to DIs [5-7].

Considering the frequent co-prescription of anti-infective agents with atypical antipsychotics, it is essential for clinicians to be aware of the potential DIs between them. Previous global reviews of DIs with atypical antipsychotics have also included DIs with anti-infective agents but were not specifically focused on these combinations [8,9]. The purpose of this article was to provide an updated review of clinically significant DIs between atypical antipsychotics and anti-infective agents.

\section{Methods of Literature Search}

After many years of writing articles on antipsychotic DIs [3,4,8], we have figured out that the challenges of finding articles are completely different compared to systematic searches for meta-analysis in which replication by other authors and elimination of low-quality articles with low level of evidence is essential. In the area of DIs, there is so little information that it is not easy to find the articles; therefore, case reports are important, and in their absence, we needed to provide orientation by extrapolating from other antipsychotics with similar pharmacokinetic characteristics. In some cases, we found that even DIs from anti-infective agents with other psychiatric drugs or non-psychiatric drugs were helpful in orienting clinicians when nothing else was available. In summary, we were not trying to exclude articles but to include any information that may help clinicians. Most of the articles that we have included in this review came from our article library on DIs accumulated after writing DI review articles on antipsychotics $[3,4,8]$, which the first and last author keep updating every day as they find articles in their clinical and/or research activities. To be sure that we were not missing any articles from prior searchers or any new articles recently published in September of 2020 we tried to use PubMed searches. PubMed has no MeSH heading for DIs, so we needed to complete many manual searches in a very complex and repetitive way. Each search was done with no time limit from the beginning of PubMed until the day in September that we completed the search. We decided to focus only on articles in English. The searches included 13 atypical antipsychotics and 61 anti-infective agents or classes, leading to 793 individual PubMed searches. Considering erythromycin, for example, we conducted 13 searches by writing in the PubMed search box "erythromycin AND amisulpride", "erythromycin AND aripiprazole" and the other 11 atypical antipsychotics. Additional relevant DI articles were also obtained from citations of the articles that were retrieved during our search. We also reviewed the Summary of Product Characteristics and Food \& Drug Administration (FDA) prescribing information for each atypical antipsychotic and the most commonly used anti-infective agents. Similarly, the Micromedex and the Liverpool DI databases were also searched for any other missing article. In all of these searchers, we only excluded meeting abstracts because they are not easy to obtain. In summary, our search resulted in 34 combinations between an atypical antipsychotic and an anti-infective agent supported by at least one DI study and 52 relevant DI articles from peer-review journals were included. The Introduction and Discussion sections were supported by additional references that helped us to provide a comprehensive review of the topic. The review of DIs in each class of anti-infective agents was summarized in a table with a practical summary of how to manage DIs within that class of anti-infective agents based on the authors' knowledge at the time of publication of this article. Each table has four columns: anti-infective, atypical antipsychotic, outcome, 
and actions. When there were studies or case reports we used them to describe outcomes and we added these references in the outcome column. Sometimes there is no published article and the outcome is based on extrapolation from other drugs with similar pharmacological characteristics or pharmacokinetic/pharmacodynamic principles; in this case, no reference is provided. The actions are ordered by letter in an effort to reflect the sequence of decisions; we are just trying to orient clinicians rather than provide strict sequences.

\section{Basic Mechanisms Involved in DIs between Atypical Antipsychotics and Anti-Infective Agents}

The various mechanisms involved in DIs can be categorized as either pharmacokinetic (PK) or pharmacodynamic (PD).

\subsection{PK DIs}

PK DIs consist of modifications in the absorption, distribution, metabolism, or excretion of a drug and/or its metabolite(s) after the addition of another drug. These DIs are associated with a change in plasma concentration of either the drug or its metabolite(s) and are easily verified by therapeutic drug monitoring (TDM).

PK DIs between atypical antipsychotics and anti-infective agents are largely mediated by drug-metabolizing enzymes, in particular, the hepatic cytochrome P450 (CYP) system and, to a lesser extent, the uridine diphosphate glucuronosyltransferase (UGT) system, and by drug transporters in the gut, liver, kidney, and brain such as the P-glycoprotein (P-gp).

The main clinically significant PK DIs between atypical antipsychotics and anti-infective agents occur at a metabolic level and result from enzyme inhibition or induction. Available knowledge of substrates, inhibitors, and inducers of the major drug-metabolizing enzymes has greatly improved the possibility of predicting and eventually avoiding potential DIs [1]. In principle, concomitant treatment with drugs metabolized by the same enzyme or coadministration of a drug with another medication acting as an inhibitor or inducer involves a DI risk. A variety of drug-related (i.e., potency and concentration/dose of the inhibitor/inducer, therapeutic index of the substrate, extent of metabolism of the substrate through the affected enzyme, presence of active metabolites), patient-related (i.e., age, genetic predisposition) and epidemiological factors (i.e., probability of concurrent use) must be taken into account when evaluating the potential occurrence, magnitude and clinical relevance of a metabolic DI [1].

PK parameters of atypical antipsychotics have been described in prior articles [3,4]. In summary, CYP1A2 is the main metabolic pathway for clozapine and olanzapine; CYP3A4 is the main pathway for cariprazine, lurasidone, and quetiapine; CYP2D6 and secondarily CYP3A4 metabolize aripiprazole, brexpiprazole, iloperidone and risperidone; renal elimination is the main way to clear amisulpride and paliperidone; aldehyde oxidase and secondarily CYP3A4 metabolize ziprasidone; and CYP1A2 and UGTs are the main pathways for asenapine. Most atypical antipsychotics appear to be neither inhibitors nor inducers of the major drug-metabolizing enzymes and only asenapine may have weak CYP2D6 inhibitory properties. Therefore, these agents are not expected to give rise to PK DIs with anti-infective agents unless unusual circumstances of saturation are present in which any drug can behave as a competitive inhibitor. On the other hand, many anti-infective drugs may cause metabolically-based DIs because they act as inhibitors or inducers of various drug-metabolizing systems. In this respect, macrolides, fluoroquinolones, isoniazid, azole antimycotics, and antiretrovirals act as strong inhibitors of CYP isoforms including CYP3A4 and CYP1A2 and may therefore impair the elimination of atypical antipsychotics metabolized via these isoforms [10-14]. Conversely, the antitubercular drug rifampin induces the activity of CYP1A2, CYP2C9, CYP2C19, and CYP3A4, as well as UGTs, thereby decreasing the plasma concentrations of a number of newer antipsychotics [15].

PK DIs between atypical antipsychotics and anti-infective agents may also involve drug transporters, in particular P-gp, a multidrug efflux transporter highly expressed in the small intestine, brain, liver, and kidney that acts as a natural defense mechanism against several drugs by limiting their 
absorption from the gut and penetration into the brain and promoting their elimination in the bile and urine. Among anti-infective drugs, a number of azole antimycotics and antivirals inhibit various drug transporters including P-gp, while rifampin is known to induce the activity of P-gp. There is some evidence suggesting that the atypical antipsychotics risperidone and paliperidone are substrates of P-gp [16,17]. In theory, inhibition of P-gp by certain anti-infective drugs may increase plasma and brain concentrations of these antipsychotics.

\subsection{PD DIs}

PD DIs occur when concomitantly administered medications share the same target sites of actions (i.e., receptor) producing additive, synergistic or antagonistic effects that can enhance or weaken the pharmacological action of either drug without any change in the plasma concentration. While the mechanisms responsible for the therapeutic effect obviously differ between newer antipsychotics and anti-infective drugs, concomitant administration of compounds of these two classes may be associated with ADRs explained by a PD DI.

As a class, antipsychotic medications have the potential to prolong the corrected QT interval (QTc), possibly leading to life-threatening ventricular arrhythmias including Torsades de Pointes (TdP). However, atypical antipsychotics vary markedly in their effects on QTc with ziprasidone and iloperidone associated with the most QTc prolongation and lurasidone, aripiprazole, brexpiprazole, and cariprazine appear to have the least association with QTc prolongation [18,19]. Medications belonging to various antimicrobial classes, including macrolides, fluoroquinolones, azole antimycotics, antiretrovirals, and antimalarials, have been associated with QTc prolongation [20]. Combined use of atypical antipsychotics with anti-infective agents known to prolong the QTc interval may result in additive effects on QTc interval prolongation, potentially leading to cardiac ADRs including TdP and/or sudden death.

Atypical antipsychotics may cause or worsen metabolic abnormalities such as weight gain, hyperglycemia, and hyperlipidemia, specifically the metabolic syndrome, which has been linked to an increased cardiovascular risk [21]. Available evidence indicates that the risk of metabolic disturbances is greatest with clozapine and olanzapine, moderate with risperidone and quetiapine, and least with aripiprazole, ziprasidone, lurasidone, brexpiprazole, and cariprazine [22]. Among anti-infective drugs, some antivirals, namely protease inhibitors, have classically been associated with the development of metabolic changes $[23,24]$. Potentiation of metabolic effects may occur when these medications are used concomitantly. Moreover, the human immunodeficiency virus (HIV) infection may be also a contributor to metabolic syndrome [25].

Various classes of anti-infective agents can complicate the treatment of patients with prior psychiatric disorders because they have the potential to cause neuropsychiatric ADRs including psychotic symptoms [26,27]. The occurrence of psychotic symptoms induced by anti-infective agents can decrease the benefits of antipsychotic agents.

Rarely some antibiotics have been associated with seizures [28]. Although it is not a well-understood topic, penicillins, cephalosporins, imipenem, and fluoroquinolones may have GABA antagonist properties [28]. All atypical antipsychotics, but clozapine foremost and secondly olanzapine and quetiapine can decrease the seizure threshold [29]. Although this potential PD DI has not been studied, we cannot rule out that in rare patients the combinations of these antibiotics and these atypical antipsychotics might contribute to seizures.

\section{DIs between Atypical Antipsychotics and Anti-Infective Agents}

\subsection{Antibiotics}

Antibiotics are among the most commonly prescribed drugs and many have properties that predispose them to clinically significant DIs. Antibiotics are categorized into different classes based on 
their mechanism of action, chemical structure, or spectrum of activity. In this section, only classes of antibiotic agents with documented DIs with atypical antipsychotics will be considered in detail.

\subsubsection{Macrolides}

Macrolide antibiotics, namely erythromycin, clarithromycin, and troleandomycin, are potent inhibitors of CYP3A4 and, to a lesser extent, CYP1A2, and may therefore interfere with the elimination of a number of atypical antipsychotics predominantly metabolized by these enzymes [10].

Controversial findings have been reported concerning the DIs between erythromycin and clozapine. Two case reports have indicated that concomitant treatment with erythromycin resulted in an elevation of plasma levels of clozapine, along with toxic effects such as somnolence, disorientation, dizziness, nausea, and seizures $[30,31]$. Severe infections release cytokines and inhibit CYPs, including CYP1A2, having the potential to cause a clozapine intoxication; these two case reports did not consider that possibility [32]. A subsequent randomized crossover study in 12 healthy male subjects documented that the PKs of clozapine, administered as a single dose of $12.5 \mathrm{mg}$, were not significantly modified during coadministration with erythromycin, $1500 \mathrm{mg} /$ day, suggesting a limited involvement of CYP3A4 in the metabolism of clozapine in humans [33]. This study can be criticized because, due to the short duration of the erythromycin phase, steady state was not reached in this study, and doses of clozapine used were lower than those typically used in clinical practice. On the other hand, other studies with potent CYP3A4 inhibitors [34] suggest no relevant effects on clozapine levels. In summary, erythromycin is not likely to cause clozapine intoxication but any severe infection that may be treated with erythromycin is likely to cause a clozapine intoxication.

A clinically significant PK DI may occur between macrolide antibiotics and quetiapine, a second-generation antipsychotic mainly metabolized via CYP3A4. In a PK investigation in Chinese patients with schizophrenia, 19 subjects received multiple doses of quetiapine ( $400 \mathrm{mg} /$ day) with or without co-administered erythromycin (1500 mg/day) [35]. Concomitant administration with erythromycin was associated with a significant increase in quetiapine maximal plasma concentration $\left(\mathrm{C}_{\max }\right)$, area under concentration-time curve (AUC), and terminal-phase elimination half-life time $\left(\mathrm{t}_{1 / 2}\right)$ by 68,129 , and $92 \%$, respectively, while quetiapine clearance decreased by $52 \%$. These results were explained by inhibition of CYP3A4-mediated metabolism of quetiapine by erythromycin. The potential clinical relevance of this DI is highlighted by the case of a 32-year-old man with schizoaffective disorder and metabolic syndrome who experienced a significant increase in quetiapine plasma concentration following administration of clarithromycin, another macrolide antibiotic and strong CYP3A4 inhibitor. The patient, hospitalized for acute psychotic symptoms, was started with $50 \mathrm{mg} /$ day of quetiapine with a gradual increase in dosage to $700 \mathrm{mg} /$ day over 10 days. Psychotic symptoms disappeared within 3 weeks. On day 28, the patient developed a lower respiratory infection and was treated with oral sultamicillin $750 \mathrm{mg}$ and clarithromycin $500 \mathrm{mg}$ along with his evening dose of quetiapine $400 \mathrm{mg}$. The following morning, $750 \mathrm{mg}$ sultamicillin, $500 \mathrm{mg}$ clarithromycin, and $300 \mathrm{mg}$ quetiapine were given. Within two hours the patient became somnolent, and plasma quetiapine levels were $827 \mathrm{ng} / \mathrm{mL}$ (normal range, 70 to $170 \mathrm{ng} / \mathrm{mL}$ ). The patient developed severely impaired consciousness and respiratory depression. Quetiapine overdose was suspected and treatment was discontinued. Plasma levels were continually measured over the course of 1 week until complete recovery was achieved [36].

Macrolide antibiotics may prolong the QTc interval [37]. Akathisia, a common antipsychotic ADR, has occasionally been associated with erythromycin and clarithromycin in patients not taking any antipsychotic [38]. Definitive cases of akathisia have been associated when macrolide agents are added to atypical antipsychotics [39]. 


\subsubsection{Fluoroquinolones}

Ciprofloxacin, a broad-spectrum fluoroquinolone antimicrobial, is a strong CYP1A2 and a moderate CYP3A4 inhibitor [11] with the potential to inhibit antipsychotics predominantly metabolized by CYP1A2 (clozapine, olanzapine and asenapine).

In a 72-year-old man, the addition of ciprofloxacin treatment $(1000 \mathrm{mg} /$ day $)$ on a clozapinemaintenance regimen with a low dose $(18.75 \mathrm{mg} /$ day $)$ caused a significant increase in plasma clozapine concentration and suggested an inhibitory effect of ciprofloxacin on CYP1A2 [40]. A formal PK study further investigated this possible DI [41]. In this randomized, double-blind, cross-over study involving 7 schizophrenic inpatients stabilized on clozapine (dose ranging from 150 to $400 \mathrm{mg}$ /day), concomitant administration of ciprofloxacin, $500 \mathrm{mg}$ /day for 7 days, increased mean serum concentrations of clozapine and norclozapine by $29 \%$ and $31 \%$, respectively [41]. Interestingly, these two publications involved low doses of either clozapine or ciprofloxacin. On the other hand, a case description by Gex-Fabry et al. revealed the potential for a serious PK interaction, with clozapine levels increasing by a factor of 3.4 from 354 to $1218 \mathrm{ng} / \mathrm{mL}$ after the addition of ciprofloxacin $1500 \mathrm{mg} /$ day [42]. This potential DI with ciprofloxacin was formally acknowledged by the FDA in 2005 and reflected in a change in product labeling for clozapine in December 2005. Subsequent case reports [43-47] documented that the PK DI between these two medications could lead to potentially fatal clozapine intoxications.

The possibility of a PK DI between ciprofloxacin and olanzapine mediated by CYP1A2 inhibition was suggested by a case report describing a patient on stable treatment with olanzapine whose serum concentrations were almost doubled after initiation of ciprofloxacin with a dose of $500 \mathrm{mg} /$ day [48].

The potential DI between ciprofloxacin and asenapine, a substrate of CYP1A2 and UGT1A4, was not documented by TDM but suggested by an ADR of sudden-onset dystonia in a patient taking asenapine soon after administration of $1000 \mathrm{mg} /$ day of ciprofloxacin [49].

Two other fluoroquinolones, enoxacin, and norfloxacin, are also clinically relevant inhibitors of CYP1A2 [50] but there is no documentation in the literature of a DI with atypical antipsychotics. On the other hand, levofloxacin is not believed to be a CYP1A2 inhibitor [51] and did not influence clozapine levels in a patient with pneumonia [52].

Fluoroquinolones have been associated with QTc interval prolongation [53]. Letsas et al. [54] reported the case of an elderly patient receiving olanzapine who developed a marked QTc interval prolongation after intravenous administration of ciprofloxacin.

\subsubsection{Tetracyclines}

Minocycline, a tetracycline antibiotic, has been reported to have beneficial effects on symptoms of schizophrenia when administered as an add-on to antipsychotic therapy [55]. In a study in clozapine-treated schizophrenic patients with persistent symptoms, 52 subjects were randomized to receive minocycline, at a dose of $200 \mathrm{mg} /$ day, or placebo for 10 weeks [56]. Coadministration with minocycline was associated with a statistically significant increase $(p=0.033)$ in clozapine plasma levels as compared to placebo, while no differences in plasma levels of norclozapine were found between the two groups. As minocycline has been found to increase the exposure to theophylline, a substrate for CYP1A2, it was hypothesized that inhibition of CYP1A2 may explain the increase in plasma clozapine concentrations. The article's research section did not provide data on the effect size of the inhibition but it appears not to be clinically relevant since the discussion stated, "the average increase in clozapine plasma level for the minocycline-treated group was $101.4 \mathrm{ng} / \mathrm{mL}$, approximately a 21\% increase from baseline". 


\subsubsection{Trimethoprim}

Trimethoprim is part of the combined antibiotic trimethoprim-sulfamethoxazole. Trimethoprim is an inhibitor of some renal transporters called organic cation transporters (OCTs) and multidrug and toxin extrusion transporters (MATEs) [57]. A DI study in 30 healthy males by the paliperidone marketer found no effects on paliperidone clearance, suggesting that other renal transporters should be involved in paliperidone clearance [58]. It has been estimated that in normal individuals approximately $38 \%$ of paliperidone is excreted by a renal transporter that still needs to be identified [59].

\subsubsection{Ampicillin}

Csik and Molnar [60] proposed that a case of symptoms of clozapine intoxication during sinusitis was explained by ampicillin inhibition of clozapine metabolism. As ampicillin is not known to be a CYP inhibitor [5], the case was reinterpreted by proposing that the clozapine intoxication was explained by the cytokines released during the sinusitis [32]. The lack of another report describing other cases of DIs in PubMed between clozapine and any other antipsychotic suggests that in effect ampicillin is not a CYP inhibitor. Ampicillin is very frequently used around the world including in patients taking atypical antipsychotics.

A practical summary of managing DIs between antibiotics and atypical antipsychotics is reported in Table 1. 
Table 1. Practical summary of managing drug interactions (DIs) between antibiotics and atypical antipsychotics based on the authors' knowledge at the time of publication of this article.

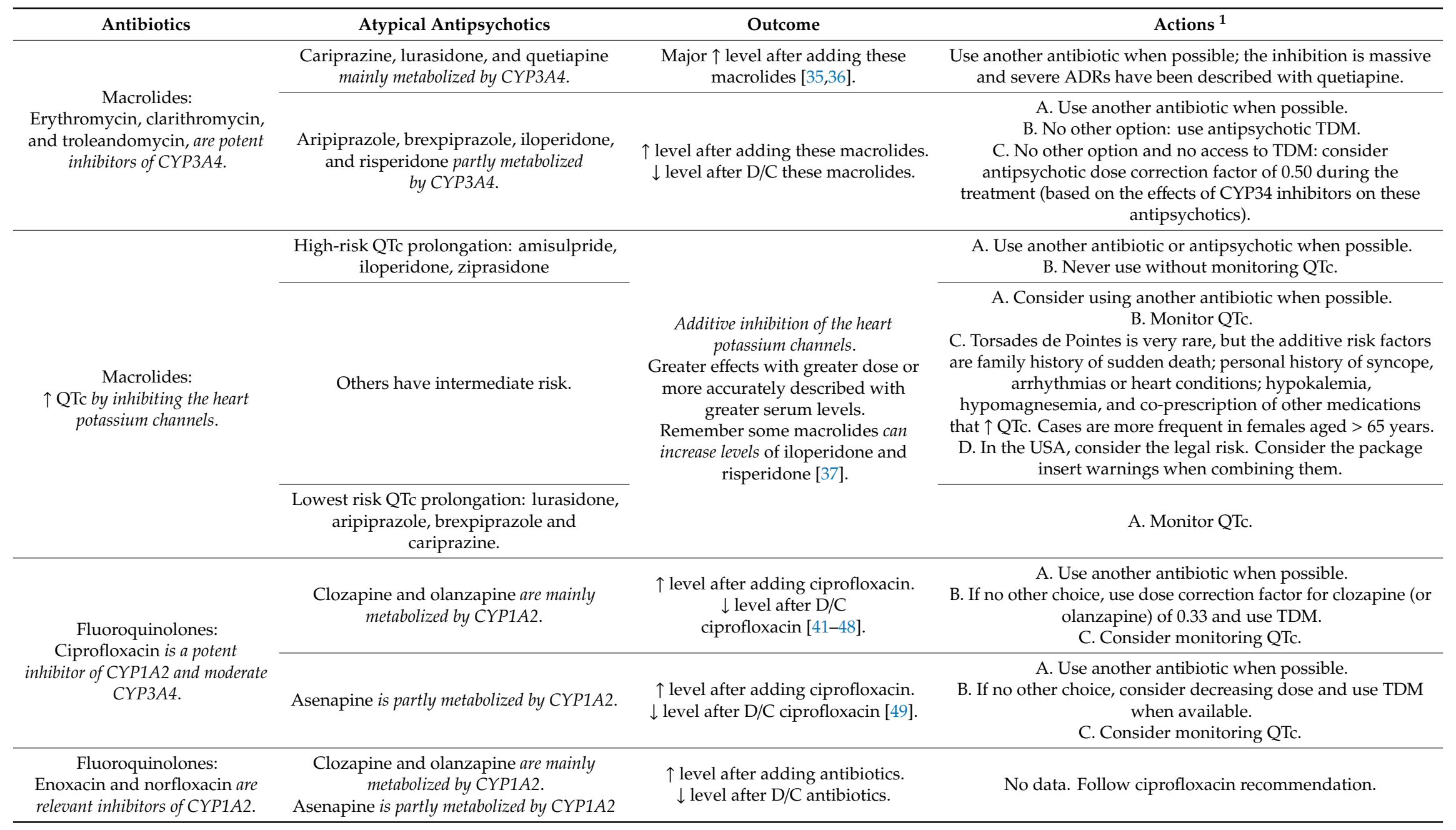


Table 1. Cont.

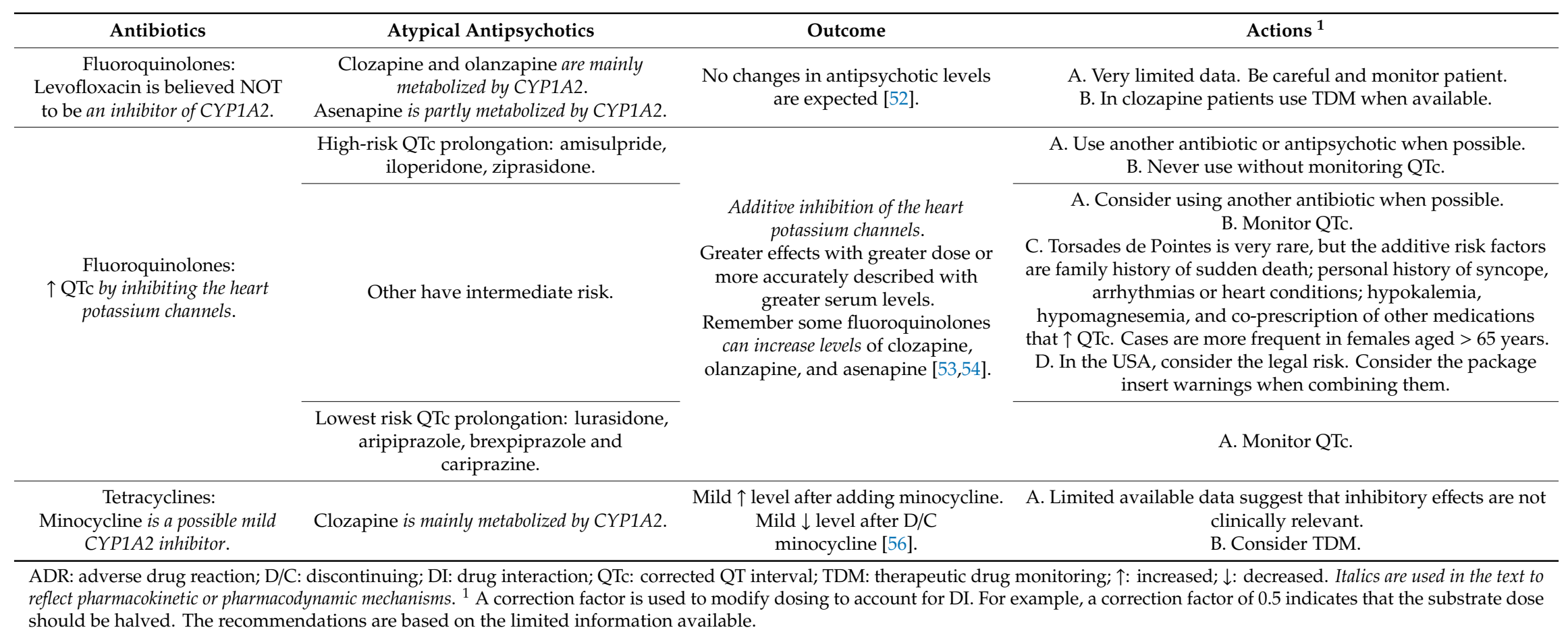




\subsection{Antitubercular Agents}

Rifampin, isoniazid, pyrazinamide, and ethambutol are first-line antitubercular medications which are FDA-approved and indicated for the treatment of mycobacterium tuberculosis. Rifampin and isoniazid are the only antituberculars with DI data with atypical antipsychotics.

\subsubsection{Rifampin}

The antitubercular agent rifampin is a potent inducer of both the hepatic and intestinal CYPs, including CYP1A2 and CYP3A4, and the P-gp transport system [15]. Thus, it is expected to induce the metabolism of most atypical antipsychotics which are cleared via CYP isoforms and/or are P-gp substrates. Generally, full induction is reached in about 1 week after starting rifampin treatment and the induction dissipates in roughly 2 weeks after discontinuing rifampin $[61,62]$. The induction is near maximal at a dose of $300 \mathrm{mg} /$ day [61].

Three case reports have documented the possibility of a PK DI between rifampin and clozapine [63-65]. The first case reported a 33-year-old male schizophrenia patient stabilized on clozapine therapy ( $400 \mathrm{mg} /$ day) who developed tuberculosis and was treated with rifampin $600 \mathrm{mg} /$ day [63]. Within 2-3 weeks, his clozapine plasma concentrations decreased approximately six-fold resulting in an exacerbation of psychotic symptoms. A second case described a loss of clozapine efficacy caused by rifampin in a 30-year-old man with schizophrenia [64]. Clozapine therapy for 3 months at $300 \mathrm{mg} /$ day controlled symptoms with some dose-related ADRs (sedation, and hypersalivation). Following diagnosis of tuberculosis, treatment with oral rifampin, $600 \mathrm{mg}$ daily as monotherapy, was started. Two weeks later, the patient no longer complained of sedation and hypersalivation, but his psychotic symptoms worsened. At the end of the month, his psychopathology was as severe as when clozapine was first initiated. The dose of clozapine was increased to $550 \mathrm{mg}$ daily with only mild improvement. Following discontinuation of rifampin after 6 months of therapy, psychotic symptoms improved significantly, while sedation and hypersalivation reappeared within 1 week. Though clozapine concentrations were not reported, fluctuations in symptomatology and ADR were probably explained by an inducing effect of rifampin on clozapine metabolism. In the third case, a 30-year-old female with paranoid schizophrenia had been relatively stable for many years on $100 \mathrm{mg} /$ day of clozapine [65]. Following the introduction of rifampin in a dose of $600 \mathrm{md} /$ day, she experienced an acute and severe psychotic relapse. Her clozapine and norclozapine plasma concentrations were subtherapeutic (less than $50 \mathrm{ng} / \mathrm{mL}$ ). After discontinuation of rifampin, the clozapine dose was slowly titrated up to $650 \mathrm{mg} /$ day (clozapine levels $400 \mathrm{ng} / \mathrm{mL}$ ) and over 2-3 months clinical symptomatology gradually improved.

Two formal PK investigations $[66,67]$ evaluated the effect of rifampin on risperidone (metabolized by CYP2D6 and, to a lesser extent, by CYP3A4). In an open, randomized two-phase crossover study involving 10 Thai male volunteers, subjects received oral risperidone $4 \mathrm{mg}$ alone or oral rifampin $600 \mathrm{mg}$ daily for 5 days followed by oral risperidone $4 \mathrm{mg}$ [66]. Concomitant administration of risperidone with rifampin was associated with a significant decrease in the AUC (by $72 \% ; p<0.01$ ), $C_{\max }$ (by $50 \%$; $p<0.05$ ) when compared with risperidone alone. A randomized, open-label, 2-way crossover study in 10 healthy Korean volunteers found similar results [67]. The pharmacokinetics of a single $1 \mathrm{mg}$ oral dose of risperidone were investigated before and after 7 days with $600 \mathrm{mg}$ rifampin or placebo. Rifampin significantly decreased the AUC of risperidone, 9-hydroxyrisperidone, and the active moiety by $51 \%, 43 \%$, and $45 \%$, respectively. These two studies provided in vivo evidence of the involvement of CYP3A4 in the metabolism of risperidone but P-gp induction may also be a contributing factor.

Lurasidone is mainly metabolized by CYP3A4. In 20 healthy volunteers, the coadministration of a single dose of lurasidone $40 \mathrm{mg}$ with rifampin $600 \mathrm{mg} /$ day at steady-state (for 8 days) resulted in a decrease in lurasidone $C_{\max }$ and AUC by approximately $85 \%$ and $82 \%$, respectively, relative to lurasidone administration alone [68]. 


\subsubsection{Isoniazid}

Isoniazid is a clinically relevant CYP1A2 inhibitor [13]. A case report described a 65-year-old Caucasian male with a clozapine concentration-dose (C/D) ratio of $0.99 \mathrm{ng} / \mathrm{mL}$ per $\mathrm{mg} / \mathrm{day}$ (and a total $\mathrm{C} / \mathrm{D}$ ratio of 1.95). The addition of isoniazid increased the $\mathrm{C} / \mathrm{D}$ (and total 1.95) ratios between 1.73-2.41 (2.73-3.82) while its discontinuation led to normalization of the clozapine C/D ratio to 1.20 (2.30) [69]. According to an in vitro study, isoniazid may be a clinically relevant CYP3A4 inhibitor [70], thus it may be a clinically relevant inhibitor of antipsychotics metabolized by CYP3A4.

A practical summary of managing DIs between antibiotics and atypical antipsychotics is included in Table 2. 
Table 2. Practical summary of managing DIs between antitubercular agents and atypical antipsychotics based on the authors' knowledge at the time of publication of this article.

\begin{tabular}{|c|c|c|c|}
\hline Antitubercular Agents & Atypical Antipsychotics & Outcome & Actions ${ }^{1}$ \\
\hline \multirow{4}{*}{$\begin{array}{l}\text { Rifampin is an inducer of } \\
\text { multiple metabolic enzymes } \\
\text { and transporters. }\end{array}$} & $\begin{array}{l}\text { Clozapine and olanzapine are } \\
\text { mainly metabolized by CYP1A2. }\end{array}$ & \multirow{4}{*}{$\begin{array}{l}\downarrow \text { level } 1 \text { week after } \\
\text { adding rifampin. } \\
\uparrow \text { level } 2 \text { weeks after } \\
\text { D/C rifampin [63-68]. }\end{array}$} & \multirow{4}{*}{$\begin{array}{l}\text { A. Consider another antitubercular agent or atypical antipsychotic when possible. } \\
\text { Amisulpride and ziprasidone may be the least influenced by induction. } \\
\text { B. No other option: use antipsychotic TDM. } \\
\text { C. No other option and no access to TDM we can only provide recommendations } \\
\text { based on the effects of potent inducers on these antipsychotics by using dose } \\
\text { correction factors of: } 2 \text { (for clozapine, olanzapine, aripiprazole, brexpiprazole, } \\
\text { iloperidone, or risperidone) and } 3 \text { (for paliperidone). } \\
\text { D. We cannot provide any dose correction factor for asenapine and access to its TDM } \\
\text { is limited. } \\
\text { E. We do not recommend combining rifampin with cariprazine, lurasidone, or } \\
\text { quetiapine even with access to TDM since, based on the effects of potent inducers } \\
\text { such as carbamazepine on these antipsychotics, the needed correction factor may be } 5 \\
\text { or even higher. }\end{array}$} \\
\hline & $\begin{array}{l}\text { Aripiprazole, brexpiprazole, } \\
\text { iloperidone and risperidone are } \\
\text { partly metabolized by CYP } 3 A 4 .\end{array}$ & & \\
\hline & $\begin{array}{c}\text { Cariprazine, lurasidone and } \\
\text { quetiapine are mainly metabolized } \\
\text { by CYP3A4. }\end{array}$ & & \\
\hline & $\begin{array}{l}\text { During induction, paliperidone } \\
\text { may be mainly metabolized } \\
\text { by CYP3A4.Pg-p induction may also } \\
\text { decrease paliperidone effects. }\end{array}$ & & \\
\hline \multirow{4}{*}{$\begin{array}{l}\text { Isoniazid is an inhibitor of } \\
\text { CYP1A2 and CYP3A4. }\end{array}$} & $\begin{array}{l}\text { Clozapine and olanzapine are } \\
\text { mainly metabolized by CYP1A2. }\end{array}$ & \multirow{4}{*}{$\begin{array}{c}\uparrow \text { level after adding } \\
\text { isoniazid. } \\
\downarrow \text { level after } \mathrm{D} / \mathrm{C} \\
\text { isoniazid [69]. }\end{array}$} & \multirow{4}{*}{$\begin{array}{l}\text { A. Consider another antituberculosis agent or atypical antipsychotic when possible. } \\
\text { Amisulpride, paliperidone and ziprasidone may be the least influenced by inhibition } \\
\text { B. No other option: use antipsychotic TDM. } \\
\text { C. No other option and no access to TDM: we can only provide recommendations } \\
\text { based on the effects of potent inhibitors on these antipsychotics by using dose } \\
\text { correction factors of: } 0.5 \text { (for clozapine, olanzapine, aripiprazole, brexpiprazole, } \\
\text { iloperidone, and risperidone). } \\
\text { D. We cannot provide any dose correction factor for asenapine and access to its TDM } \\
\text { is limited. } \\
\text { E. We do not recommend combining isoniazid with cariprazine, lurasidone or } \\
\text { quetiapine unless clinician has expertise in their TDM. }\end{array}$} \\
\hline & $\begin{array}{l}\text { Aripiprazole, brexpiprazole, } \\
\text { iloperidone, and risperidone are } \\
\text { partly metabolized by CYP3A4. }\end{array}$ & & \\
\hline & $\begin{array}{c}\text { Cariprazine, lurasidone, } \\
\text { and quetiapine are mainly } \\
\text { metabolized by CYP3A4. }\end{array}$ & & \\
\hline & $\begin{array}{c}\text { Asenapine is partly metabolized } \\
\text { by CYP1A2. }\end{array}$ & & \\
\hline
\end{tabular}




\subsection{Antifungals}

Azole antimycotics have the potential to cause clinically significant DIs when co-administered with atypical antipsychotics.

Azole Antimycotics

Azole antifungal drugs (namely, fluconazole, itraconazole, ketoconazole, posaconazole, and voriconazole) are used frequently in a clinical setting for prophylaxis or treatment of systemic fungal infections. They are CYP and P-gp inhibitors [12]. Their inhibitory potential varies greatly: itraconazole, ketoconazole, and posaconazole are more potent inhibitors of CYP3A4 than are fluconazole or voriconazole [12]. In addition to CYP3A4, fluconazole and voriconazole are also strong noncompetitive or mixed-type inhibitors of CYP2C9 and CYP2C19 [71].

Ketoconazole has been tested in clinical studies during the development of various atypical antipsychotics that are metabolized by CYP3A4 [9].

In 27 patients treated with quetiapine, concomitant administration of ketoconazole, $400 \mathrm{mg} /$ day, resulted in a 4 -fold increase in a mean quetiapine peak plasma concentration [72]. In 12 healthy volunteers receiving $25 \mathrm{mg}$ quetiapine before and after 4 days of treatment with ketoconazole $200 \mathrm{mg}$ daily, concomitant use of ketoconazole increased the mean $\mathrm{C}_{\max }$ and AUC of quetiapine by $235 \%$ and $522 \%$, respectively, and decreased its clearance by $84 \%$ [73]. In a study in 10 healthy subjects, coadministration of a single dose of lurasidone $10 \mathrm{mg}$ with ketoconazole $400 \mathrm{mg} /$ day at steady state (for 5 days) caused a 9.3-fold increase in lurasidone AUC, and a 6.8-fold increase in $\mathrm{C}_{\max }$, as compared to lurasidone alone [68]. These findings are consistent with inhibition of CYP3A4 by ketoconazole.

In an open-label, randomized, crossover study conducted in 10 healthy male volunteers, the PKs of a single oral dose of $2 \mathrm{mg}$ of risperidone were investigated alone or in combination with ketoconazole, $200 \mathrm{mg} /$ day for 3 days [74]. Ketoconazole pretreatment resulted in a significant increase in the AUC of risperidone by $67 \%(p<0.001)$ and a decrease in its clearance by $35 \%(p<0.05)$.

In a placebo-controlled, randomized, crossover study in 14 healthy subjects, concomitant administration of ziprasidone, given as a single dose of $40 \mathrm{mg}$, with ketoconazole, $400 \mathrm{mg} /$ day for 2 weeks, was associated with a modest increase in ziprasidone exposure [75]. Mean $C_{\max }$ and AUC of ziprasidone increased significantly $(p<0.05)$ by $34 \%$ and by $33 \%$, respectively, as compared with placebo.

Two studies in patients with schizophrenia have investigated the possibility of a PK DI between azole antimycotics and clozapine. A double-blind, placebo-controlled, randomized study, performed in 7 schizophrenia patients, documented no significant changes in PK parameters of clozapine during coadministration with itraconazole, $200 \mathrm{mg} /$ day for one week [76]. In a study involving 5 schizophrenia patients, a single clozapine dose of $50 \mathrm{mg}$ was given before and after 7 days of co-administration with ketoconazole $400 \mathrm{mg} /$ day [77]. PK parameters of clozapine and its two major metabolites, norclozapine and clozapine- $N$-oxide, did not change significantly during ketoconazole co-administration. The findings of these two studies indicate that CYP3A4 inhibition may not be clinically significant compared to CYP1A2.

Jung et al. [78] investigated the effect of a treatment with itraconazole, $200 \mathrm{mg} /$ day for a week, on plasma concentrations of risperidone and its active metabolite in 19 schizophrenia patients stabilized on risperidone therapy ( $2-8 \mathrm{mg} /$ day) in relation to CYP2D6 genotype. Itraconazole increased the mean steady-state plasma concentrations of risperidone active fraction by $71 \%$ and $73 \%$ in CYP2D6 extensive and poor metabolizers, respectively. As the ratio of risperidone/9-OH-risperidone, an index of CYP2D6 activity was not affected by itraconazole administration, this DI was attributed to inhibition of CYP3A4, an isoform playing a secondary role in the 9-hydroxylation of risperidone. In another PK investigation, coadministration of itraconazole, $100 \mathrm{mg} /$ day for 7 days, to 24 healthy male volunteers increased the $\mathrm{C}_{\max }$, the AUC, and the half-life of aripiprazole and its main metabolite by $19.4 \%, 48.0 \%$, and $18.6 \%$ and by $18.6 \%, 38.8 \%$, and $53.4 \%$, respectively [79]. 
The PK of single doses of lurasidone $(20 \mathrm{mg})$ were investigated in 11 healthy normal-weight volunteers and 13 otherwise healthy obese subjects before and during the administration of posaconazole, $300 \mathrm{mg} /$ day [80]. During posaconazole coadministration, the AUC of lurasidone increased by a factor of 6.2 in normal volunteers and by a factor of 4.9 in obese subjects, reflecting the strong inhibitory effect of posaconazole on CYP3A4 activity.

Azole antifungal agents are known to cause QT interval prolongation [81]. Therefore, concomitant use of newer antipsychotics with azole antimycotics may result in overlapping cardiac toxicity.

Ketoconazole was studied under very well-controlled randomized conditions but eliminating patients with cardiac risk. In the study funded by the ziprasidone marketer, $400 \mathrm{mg} /$ day of ketoconazole was added to 2 atypical antipsychotics [82]. In 31 patients taking $160 \mathrm{mg} /$ day ziprasidone led to a mean QTc increase of $15.9 \mathrm{~ms}$ from baseline with almost no change after adding ketoconazole. In 27 patients, taking $750 \mathrm{mg} /$ day of quetiapine led to a mean QTc increase of $5.7 \mathrm{~ms}$ from baseline with some increase after adding ketoconazole (value in figure was estimated to be around $8 \mathrm{~ms}$ ). In the study funded by the iloperidone marketer, $400 \mathrm{mg} /$ day of ketoconazole was added to 3 atypical antipsychotics [83]. Adding ketoconazole in 35 patients taking $160 \mathrm{mg} /$ day ziprasidone led to a mean QTc increase of $15.9 \mathrm{~ms}$ from baseline and $6 \mathrm{~ms}$ from only ziprasidone. Adding ketoconazole, in 35 patients taking $750 \mathrm{mg} /$ day of quetiapine led to a mean QTc increase of $2.6 \mathrm{~ms}$ from baseline. Adding ketoconazole in 39 patients taking $16 \mathrm{mg} /$ day of iloperidone and $20 \mathrm{mg} /$ day of paroxetine the QTc increased as an average $15.7 \mathrm{~ms}$ from baseline. Adding ketoconazole in 39 patients taking $24 \mathrm{mg} /$ day of iloperidone and $20 \mathrm{mg} /$ day of paroxetine the QTc increased as an average $19.3 \mathrm{~ms}$ compared to baseline. Adding ketoconazole in 35 patients taking $48 \mathrm{mg} / \mathrm{day}$ of iloperidone and $20 \mathrm{mg} /$ day of paroxetine the QTc increased as an average $19.5 \mathrm{~ms}$ compared to baseline. In summary, in this ketoconazole dose and in these selected patients in those two antipsychotic trials, the effects of ketoconazole on QTc appear to be mainly explained by a PK DI and there were limited effects of the increase of QTc due to PD cardiac effects of ketoconazole.

All azoles had the risk of further QTc prolongation when prescribed with any atypical antipsychotic and this may be potentiated by their PK effects.

A practical summary of managing DIs between antibiotics and atypical antipsychotics is reported in Table 3. 
Table 3. Practical summary of managing DIs between antifungals and atypical antipsychotics based on the authors' knowledge at the time of publication of this article.

\begin{tabular}{|c|c|c|c|}
\hline Antifungals & Atypical Antipsychotics & Outcome & Actions \\
\hline \multirow{5}{*}{$\begin{array}{c}\text { Itraconazole, ketoconazole, } \\
\text { and posaconazole are potent } \\
\text { inhibitors of CYP3A4 and they } \\
\text { prolong QTc by inhibiting the heart } \\
\text { potassium channels. }\end{array}$} & $\begin{array}{c}\text { Cariprazine, lurasidone, and quetiapine are } \\
\text { mainly metabolized by CYP3A4. }\end{array}$ & \multirow{5}{*}{$\begin{array}{c}\uparrow \text { level of CYP3A4 } \\
\text { antipsychotics after } \\
\text { adding azole. } \\
\downarrow \text { level of CYP3A4 } \\
\text { antipsychotics after D/C azole. } \\
\text { Additive effects on QTc } \\
\text { prolongation [72-83]. }\end{array}$} & \multirow{5}{*}{$\begin{array}{l}\text { A. Do not use combinations of these azoles with atypical } \\
\text { antipsychotics metabolized by CYP3A4 (cariprazine, lurasidone, } \\
\text { quetiapine, aripiprazole, brexpiprazole, iloperidone, } \\
\text { and risperidone). } \\
\text { B. Do not use combinations of these azoles with atypical } \\
\text { antipsychotics with high risk of QTc prolongation (amisulpride, } \\
\text { iloperidone, and ziprasidone). } \\
\text { C. Adding these azoles to clozapine, olanzapine, } \\
\text { and paliperidone may have minimal inhibitory effects on their } \\
\text { metabolism but additive effects on QTc prolongation should be } \\
\text { expected. Monitoring QTc is recommended. }\end{array}$} \\
\hline & $\begin{array}{c}\text { Aripiprazole, brexpiprazole, iloperidone, } \\
\text { and risperidone are partly metabolized } \\
\text { by CYP3A4. }\end{array}$ & & \\
\hline & $\begin{array}{l}\text { Clozapine and olanzapine are mainly } \\
\text { metabolized by CYP1A2. }\end{array}$ & & \\
\hline & Asenapine is partly metabolized by $C Y P 1 A 2$. & & \\
\hline & $\begin{array}{l}\text { Inhibition of metabolism of amisulpride may be } \\
\text { minimal and of ziprasidone may be small but } \\
\text { they cause greater prolongation of QTc interval } \\
\text { by inhibiting the heart potassium channels. }\end{array}$ & & \\
\hline \multirow{3}{*}{$\begin{array}{l}\text { Fluconazole and voriconazole } \\
\text { appear to be mild to moderate CYP3A4 } \\
\text { inhibitors but they prolong QTc by } \\
\text { inhibiting the heart } \\
\text { potassium channels. }\end{array}$} & $\begin{array}{l}\text { High-risk QTc prolongation: amisulpride, } \\
\text { iloperidone, ziprasidone. }\end{array}$ & \multirow{3}{*}{$\begin{array}{l}\text { Additive effects on QTc } \\
\text { prolongation [81]. }\end{array}$} & $\begin{array}{l}\text { A. Use another antifungal or antipsychotic when possible. } \\
\text { B. Never use without monitoring QTc. }\end{array}$ \\
\hline & $\begin{array}{l}\text { Others have intermediate risk. } \\
\text { More risk for those depending on CYP3A4 for } \\
\text { their metabolism (quetiapine and risperidone). }\end{array}$ & & $\begin{array}{l}\text { A. Consider using another antifungal when possible. } \\
\text { B. Monitor QTc. } \\
\text { B. Monitor TDM for quetiapine and risperidone. } \\
\text { D. Torsades de Pointes is very rare, but the additive risk factors } \\
\text { are family history of sudden death; personal history of syncope, } \\
\text { arrhythmias, or heart conditions; hypokalemia, } \\
\text { hypomagnesemia, and co-prescription of other medications that } \\
\uparrow \text { QTc. Cases are more frequent in females aged }>65 \text { years. } \\
\text { E. In the USA, consider the legal risk. Consider the package } \\
\text { insert warnings when combining them. }\end{array}$ \\
\hline & $\begin{array}{l}\text { Lowest risk QTc prolongation: lurasidone, } \\
\text { aripiprazole, brexpiprazole and cariprazine. }\end{array}$ & & A. Monitor QTc. \\
\hline
\end{tabular}

D/C: Discontinuing; DI: drug interaction; QTc: corrected QT interval; TDM: therapeutic drug monitoring; $\uparrow$ : increased; $\downarrow$ : decreased. Italics are used in the text to reflect pharmacokinetic or pharmacodynamic mechanisms. 


\subsection{Antivirals}

Pharmacological treatment of viral infections has evolved significantly over the last decades with a large number of new agents actually available. The prevalence of some severe viral infections including HIV, hepatitis B, and hepatitis $C$ in patients with severe psychiatric disorders is much higher than in the general population [84]. Many people with psychiatric problems engage in behaviors that increase their risk of infection with blood-borne viruses, including intravenous drug use resulting from co-occurring substance misuse problems and unprotected sex with multiple partners. Atypical antipsychotic drugs are frequently co-prescribed with antiviral agents used to treat these severe infections, possibly resulting in clinically significant DIs.

\subsubsection{Antiretrovirals}

Psychotic symptoms are relatively common in patients with HIV, so that antipsychotics and antiretroviral agents may be prescribed in combination. Antiretroviral drugs include various classes such as nucleoside/nucleotide reverse transcriptase inhibitors (i.e., zidovudine, lamivudine, abacavir, emtricitabine, tenofovir), non-nucleoside reverse transcriptase inhibitors (i.e., delavirdine, efavirenz, nevirapine, etravirine, rilpivirine), and protease inhibitors (i.e., atazanavir, darunavir, fosamprenavir, indinavir, lopinavir, nelfinavir, ritonavir, saquinavir). Many antiretroviral drugs are prone to PK DIs because they are substrates as well as inhibitors of inducers of several CYP isoforms [14].

All members of the protease inhibitor class are particularly strong inhibitors of CYP3A4, with ritonavir being the most potent. Indeed, this drug is commonly used at low doses in HIV treatment $(100-200 \mathrm{mg} / \mathrm{d})$ not for its antiviral activity but rather to take advantage of its inhibition of CYP3A4, which "boosts" the plasma concentrations of co-administered protease inhibitors and thereby allows for once-daily dosing. Ritonavir has a greater potential for DI than other protease inhibitors because it also inhibits CYP2D6. Moreover, ritonavir and indinavir are potent inducers of CYP1A2 and UGT. In addition, protease inhibitors are also substrates and inhibitors of P-gp. Non-nucleoside reverse transcriptase inhibitors also have a variety of effects on CYP isoforms. With regard to this, efavirenz, nevirapine, and etravirine are inducers of CYP3A4, whereas efavirenz and etravirine are inhibitors of CYP2C9 and CYP2C19. Rilpivirine does not substantially affect CYP3A4 and is therefore less commonly involved in DI than other members of this class.

Modern combination antiretroviral therapy consists of at least three antiretroviral agents which may obviously enhance the risk of DIs. Clinically relevant DIs between antiretrovirals and psychotropic drugs including atypical antipsychotics have recently been reviewed $[85,86]$.

A clinically significant DI may occur when risperidone is co-administered with protease inhibitors. A number of case reports have documented the occurrence of ADRs such as extrapyramidal symptoms [87], reversible coma [88], neuroleptic malignant syndrome [89], and late-onset angioedema [90] in patients receiving risperidone associated with ritonavir/indinavir, presumably due to inhibition of risperidone metabolism. As ritonavir is known to be a strong inhibitor of both CYP3A4 and CYP2D6 and indinavir is known to inhibit CYP3A4, concomitant administration of indinavir or ritonavir would be expected to alter metabolism of risperidone.

Quetiapine is also a CYP3A4 substrate and concomitant treatment with ritonavir and other protease inhibitors can increase its serum concentrations. Pollack et al. [91] described two patients who developed weight gain and hyperglycemia (first case) and marked sedation and mental confusion (second case) after the addition of quetiapine to an antiretroviral regimen containing ritonavir and atazanavir. As with ritonavir, atazanavir is also a moderate inhibitor of CYP3A4. While there are no specific recommendations in the quetiapine labeling for dose adjustments with protease inhibitors, if concurrent use is necessary, the quetiapine dose should be reduced to one-sixth of the original dose [86]. Hantson et al. [92] described a case of quetiapine overdose (total $8000 \mathrm{mg}$ ingested) in a 47-year-old female patient concomitantly taking lamivudine ( $300 \mathrm{mg} /$ day), ritonavir $(100 \mathrm{mg} /$ day), atazanavir ( $350 \mathrm{mg} /$ day), and tenofovir ( $245 \mathrm{mg} /$ day) for an HIV infection. Major clinical complications consisted of a deep coma and sustained hypotension. The PK data documented a quetiapine half-life of $62 \mathrm{~h}$, 
which is 10 times the half-life reported in quetiapine's package insert, and still nearly 3 times the 22-h terminal elimination half-life calculated for a patient following quetiapine overdose ( $3000 \mathrm{mg})$ in the absence of CYP3A4 inhibitors [93]. Such a prolonged terminal half-life of quetiapine observed in this case was explained either by CYP3A4 saturation in overdose conditions or by CYP3A4 inhibition by concomitant medications.

Aripiprazole is metabolized by CYP2D6 and CYP3A4. Two case reports are available describing ADRs with the co-administration of aripiprazole and antiretroviral therapy. The first case describes an antiretroviral regimen including darunavir boosted with ritonavir, and concomitant aripiprazole, duloxetine, and buspirone [94], which led to multiple hospital admissions as well as supratherapeutic aripiprazole serum concentrations attributed to a DI between aripiprazole and the antiretroviral therapy. Conversely, in a case of a patient receiving antiretroviral containing a ritonavir-boosted protease inhibitor, the patient experienced lower-than-expected aripiprazole serum levels with clinical worsening after being converted from oral to depot aripiprazole using the manufacturer's recommended conversion [95]. The patient was ultimately stabilized on double the recommended monthly dose.

Lurasidone is primarily metabolized via CYP3A4. Ritonavir and other protease inhibitors, such as nelfinavir and saquinavir, are specifically mentioned in the lurasidone package insert as examples of strong CYP3A4 inhibitors which are contraindicated with lurasidone. Atazanavir is a moderate CYP3A4 inhibitor and lurasidone dose should be halved when given with atazanavir. Despite these theoretical interactions, there is limited information on these expected DI. Naccarato et al. reported the case of a 63-year-old HIV patient, concomitantly treated with lurasidone and atazanavir, who developed extrapyramidal symptoms associated with elevated serum concentrations of lurasidone. Extrapyramidal adverse effects disappeared following atazanavir discontinuation [96]. One major confounder in this case was the possible contribution of concomitant risperidone to parkinsonian symptoms.

Olanzapine is metabolized via CYP1A2 and UGT1A4. Ritonavir can induce CYP1A2 and UGTs, thus raising concern about the possibility of subtherapeutic olanzapine levels with coadministration. In an open-label crossover study in 14 healthy volunteers, the PKs of a single $10 \mathrm{mg}$ oral dose of olanzapine were investigated before and during coadministration of ritonavir, 600-1000 mg/day [97]. Administration of ritonavir resulted in a significant $53 \%$ decrease in olanzapine AUC $(p<0.001)$, in a significant decrease in olanzapine half-life from $32 \mathrm{~h}$ to $16 \mathrm{~h}(p<0.0001)$, and in a significant increase in olanzapine clearance $(p<0.001)$. The ritonavir doses in this particular study are much higher than in modern practice. Another open-label crossover study, conducted in 20 healthy subjects, investigated the DI between olanzapine and ritonavir, employing a $200 \mathrm{mg} /$ day dose of ritonavir, which more accurately reflects modern-day practice [98]. Increasing the olanzapine dose by $50 \%$ (from 10 to $15 \mathrm{mg} /$ day) when co-administered with fosamprenavir $700 \mathrm{mg} /$ ritonavir $200 \mathrm{mg} /$ day (for 16 days) compensated for the induction (of CYP1A2- and UGT-mediated) olanzapine metabolism and resulted in olanzapine exposure that was comparable to when olanzapine $10 \mathrm{mg}$ was administered alone. Based on the results of these studies, a $50 \%$ increase in olanzapine dose is warranted when given concomitantly with ritonavir containing antiretroviral regimens.

Being a potent inducer of CYP3A4, efavirenz may decrease plasma concentrations of some newer antipsychotics and reduce their efficacy.

In addition to potential PK DIs, concomitant use of newer antipsychotics with antiretrovirals may be associated with ADR potentiation by PD mechanisms.

Both newer antipsychotics and antiretrovirals, in particular protease inhibitors, are associated with metabolic abnormalities such as weight gain, hyperglycemia, and hyperlipidemia. Concerning protease inhibitors, these ADRs were reported more often with older agents (i.e., ritonavir) than with newer compounds (i.e., darunavir and atazanavir) $[23,99,100]$. Despite the high rate of HIV and psychiatric comorbidity and the known metabolic effects of atypical antipsychotics and antiretrovirals, the metabolic consequences of this combined treatment have received virtually no coverage in the literature. With regard to this, a retrospective study including 2229 patients with HIV and severe 
mental illness, examined the effect of concurrent use of atypical antipsychotics and antiretrovirals on metabolic parameters associated with increased cardiovascular risk [101]. Patients treated with both antiretrovirals and atypical antipsychotics were more likely to have higher blood pressure, higher diabetes prevalence, and higher serum triglycerides as compared to those only taking an atypical antipsychotic. General recommendations for the management of overlapping metabolic toxicities in patients receiving both antiretrovirals and newer antipsychotics include evaluating underlying risk, monitoring laboratory parameters, encouraging lifestyle modifications, switching agents if possible or adding additional therapy, communicating among providers, and providing patient education [99].

A potential PD DI that may occur when combining atypical antipsychotics with a number of antiretrovirals is additive QTc prolongation. Among antiretrovirals, the protease inhibitors lopinavir, nelfinavir, ritonavir and saquinavir, and the non-nucleoside reverse transcriptase inhibitors efavirenz and rilpivirine have been associated with QTc prolongation [20,102].

Clozapine has been documented to be effective in HIV patients with refractory schizophrenia. However, its use is associated with the risk of hematologic toxicity resulting in leukopenia, neutropenia, and potentially fatal agranulocytosis. Of the antiretrovirals, zidovudine is known to have myelosuppressive effects [103]. Their combined use should be avoided. While psychosis is a recognized manifestation of HIV, psychotic symptoms may be secondary to certain antiretrovirals including efavirenz, zidovudine, nevirapine, and ganciclovir [104-106] and they may theoretically reduce the benefits of concomitantly administered atypical antipsychotics.

\subsubsection{Direct-Acting Antivirals}

For several years, pegylated interferon- $\alpha$ and ribavirin have been the only available treatment for chronic hepatitis $C$ virus (HCV). Since the development of novel direct-acting antivirals these agents are no longer used. There are three main classes of direct-acting antivirals, depending on the nonstructural protein that target for inhibition: NS3/4A protease inhibitors (boceprevir, telaprevir, simeprevir, grazoprevir, paritaprevir, glecaprevir, voxilaprevir), NS5A inhibitors (ledipasvir, daclatasvir, ombitasvir, elbasvir, velpatasvir, pibrentasvir) and NS5B polymerase inhibitors (sofosbuvir, dasabuvir). These agents are usually given in combinations of two to up to five drugs, thereby enhancing the possibility of DIs.

Each of the available direct-acting antivirals has its own metabolism and presents a different potential for DIs [107]. Moreover, these agents can potentially interact with a variety of psychotropic agents via CYPs and P-gp. Smolders et al. reviewed DIs between the first approved direct-acting antivirals and other concomitant medications including antipsychotics [108]. A recent review by Roncero et al. has specifically assessed the DI potential of each of the currently available direct-acting antivirals with psychotropic drugs [109]. Though these agents are frequently co-prescribed with atypical antipsychotics, no study has investigated the possibility of DIs between agents of these two classes. Based on theoretical knowledge of the PK properties of drugs [108,109], boceprevir, simeprevir, the combination regimen paritaprevir/ombitasvir/ritonavir/dasabuvir and the combination elbasvir/grazoprevir are the most likely direct-acting antivirals to cause DIs with some antipsychotics via the inhibition of CYP3A4 and/or P-gp (paliperidone). On the other hand, no clinically significant DIs are expected when atypical antipsychotics are co-administered with the most commonly used combination regimens including velpatasvir/sofosbuvir and glecaprevir/pibrentasvir.

A practical summary of managing DIs between antibiotics and atypical antipsychotics is included in Table 4. 
Table 4. Practical summary of managing DI between antivirals and atypical antipsychotics based on the authors' knowledge at the time of publication of this article.

\begin{tabular}{|c|c|c|c|}
\hline Antivirals & Atypical Antipsychotics & Outcome & Actions \\
\hline \multirow{3}{*}{$\begin{array}{l}\text { Antiretrovirals: } \\
\text { Ritonavir is a potent inhibitor of CYP3A4, } \\
\text { CYP2D6, and P-gp and an inducer of } \\
\text { CYP12 and UGT. It prolongs QTc by } \\
\text { inhibiting the heart potassium channels. }\end{array}$} & $\begin{array}{c}\text { Cariprazine, lurasidone, and quetiapine } \\
\text { are mainly metabolized by CYP3A4. } \\
\text { Aripiprazole, brexpiprazole, iloperidone, } \\
\text { and risperidone are partly metabolized } \\
\text { by CYP3A4. }\end{array}$ & $\begin{array}{c}\uparrow \text { level of these antipsychotics after } \\
\text { adding ritonavir. } \\
\downarrow \text { level of these antipsychotics after D/C ritonavir. } \\
\text { Additive effects on QTc } \\
\text { prolongation }[20,87-96,102] \text {. }\end{array}$ & $\begin{array}{l}\text { A. Do not combine ritonavir with these } \\
\text { antipsychotics. Serious ADRs have been described } \\
\text { B. If you decide to take the risk of combining them } \\
\text { use antipsychotic TDM and QTc monitoring. }\end{array}$ \\
\hline & $\begin{array}{l}\text { Clozapine and olanzapine are mainly } \\
\text { metabolized by CYP1A2. }\end{array}$ & $\begin{array}{l}\downarrow \text { level after adding ritonavir. } \\
\uparrow \text { level after D/C ritonavir. } \\
\text { Additive effects on QTc } \\
\text { prolongation }[20,97,98,102] .\end{array}$ & $\begin{array}{l}\text { A. Consider alternatives. } \\
\text { B. Use TDM for better dosing of clozapine and } \\
\text { olanzapine. } \\
\text { C. Monitor QTc. }\end{array}$ \\
\hline & $\begin{array}{c}\text { Asenapine is metabolized by UGT } \\
\text { and CYP1A2. }\end{array}$ & $\begin{array}{c}\text { Likely } \downarrow \text { level after adding ritonavir. } \\
\text { Likely } \uparrow \text { level after D/C ritonavir. } \\
\text { Additive effects on QTc prolongation [20,102]. }\end{array}$ & $\begin{array}{l}\text { A. Do not combine ritonavir with asenapine. } \\
\text { There is no data to provide recommendations. }\end{array}$ \\
\hline \multirow{2}{*}{$\begin{array}{c}\text { Antiretrovirals: } \\
\text { Indinavir is an inducer of CYP12 and UGT. } \\
\text { It prolongs QTc by inhibiting the heart } \\
\text { potassium channels. }\end{array}$} & $\begin{array}{l}\text { Clozapine and olanzapine are mainly } \\
\text { metabolized by CYP1A2. }\end{array}$ & $\begin{array}{l}\downarrow \text { level after adding indinavir. } \\
\quad \uparrow \text { level after D/C indinavir. } \\
\text { Additive effects on QTc prolongation. }\end{array}$ & $\begin{array}{l}\text { A. Consider alternatives. } \\
\text { B. Use TDM for better dosing clozapine and } \\
\text { olanzapine. } \\
\text { C. Monitor QTc. }\end{array}$ \\
\hline & $\begin{array}{c}\text { Asenapine is metabolized by UGT } \\
\text { and CYP1A2. }\end{array}$ & $\begin{array}{l}\text { Likely } \downarrow \text { level after adding indinavir. } \\
\text { Likely } \uparrow \text { level after } \mathrm{D} / \mathrm{C} \text { indinavir. } \\
\text { Additive effects on QTc prolongation. }\end{array}$ & $\begin{array}{l}\text { A. Do not combine indinavir with asenapine. } \\
\text { There is no data to provide recommendations. }\end{array}$ \\
\hline \multirow{2}{*}{$\begin{array}{l}\text { Antiretrovirals: } \\
\text { Efavirenz, nevirapine, and etravirine are } \\
\text { CYP3A4 inducers. They prolong QTc by } \\
\text { inhibiting the heart potassium channels. }\end{array}$} & $\begin{array}{c}\text { Cariprazine, lurasidone, and quetiapine } \\
\text { are mainly metabolized by CYP3A4. } \\
\text { Aripiprazole, brexpiprazole, } \\
\text { and risperidone are partly metabolized } \\
\text { by CYP3A4. }\end{array}$ & $\begin{array}{l}\downarrow \text { level after adding antivirals. } \\
\uparrow \text { level after D/C antivirals. } \\
\text { Additive effects on QTc prolongation [20,102]. }\end{array}$ & $\begin{array}{l}\text { A. Consider alternatives. } \\
\text { B. Use TDM for better dosing these antipsychotics } \\
\text { C. Monitor QTc. }\end{array}$ \\
\hline & $\begin{array}{l}\text { High-risk QTc prolongation: } \\
\text { amisulpride, iloperidone, ziprasidone. }\end{array}$ & $\begin{array}{c}\text { Additive effects on QTc prolongation. } \\
\downarrow \text { level of iloperidone after adding antivirals. } \\
\uparrow \text { level of iloperidone after D/C } \\
\text { antivirals }[20,102] \text {. }\end{array}$ & A. Do not combine. \\
\hline \multirow{2}{*}{$\begin{array}{c}\text { Antiretrovirals: } \\
\text { Nelfinavir and saquinavir are strong } \\
\text { inhibitors of CYP3A4 } \\
\text { Atazanavir is a moderate inhibitor of } \\
\text { CYP3A4. They prolong QTc by inhibiting } \\
\text { the heart potassium channels. }\end{array}$} & $\begin{array}{c}\text { Cariprazine, lurasidone, and quetiapine } \\
\text { are mainly metabolized by CYP3A4. } \\
\text { Aripiprazole, brexpiprazole, } \\
\text { and risperidone are partly metabolized } \\
\text { by CYP3A4. }\end{array}$ & $\begin{array}{l}\qquad \text { level after adding antivirals. } \\
\downarrow \text { level after D/C antivirals. } \\
\text { Additive effects on QTc prolongation }[20,102] .\end{array}$ & $\begin{array}{l}\text { A. Consider alternatives. } \\
\text { B. Use TDM for better dosing of these } \\
\text { antipsychotics. } \\
\text { C. Monitor QTc. }\end{array}$ \\
\hline & $\begin{array}{l}\text { High-risk QTc prolongation: } \\
\text { amisulpride, iloperidone, ziprasidone. }\end{array}$ & $\begin{array}{l}\text { Additive effects on QTc prolongation [20,102]. } \\
\uparrow \text { level of iloperidone after adding antiviral. } \\
\downarrow \text { level of iloperidone after D/C antiviral. }\end{array}$ & A. Do not combine. \\
\hline
\end{tabular}


Table 4. Cont.

\begin{tabular}{|c|c|c|c|}
\hline Antivirals & Atypical Antipsychotics & Outcome & Actions \\
\hline $\begin{array}{l}\text { Antiretrovirals: } \\
\text { Zidovudine has risk of bone marrow } \\
\text { suppression }\end{array}$ & $\begin{array}{l}\text { Clozapine can cause agranulocytosis } \\
\text { possibly due to immunological mechanisms. }\end{array}$ & Additive effects cannot be ruled out. & A. Do not combine. \\
\hline $\begin{array}{l}\text { Direct-acting antivirals: Boceprevir, } \\
\text { simeprevir, the combination } \\
\text { paritaprevir/ombitasvir/ritonavir/dasabuvir } \\
\text { and the combination of } \\
\text { elbasvir/grazoprevir are CYP3A4 and/or } \\
\text { P-gp inhibitors. }\end{array}$ & $\begin{array}{l}\text { Cariprazine, lurasidone and quetiapine } \\
\text { are mainly metabolized by CYP3A4. } \\
\text { r, Aripiprazole, brexpiprazole, iloperidone, } \\
\text { and risperidone are partly metabolized } \\
\text { by CYP3A4. }\end{array}$ & $\begin{array}{c}\uparrow \text { level after adding antivirals. } \\
\downarrow \text { level after D/C antivirals }[108,109] .\end{array}$ & $\begin{array}{l}\text { A. Consider alternatives. } \\
\text { B. Use TDM for better dosing these antipsychotics. }\end{array}$ \\
\hline
\end{tabular}

ADR: adverse drug reaction; D/C: discontinuing; DI: drug interaction; QTc: corrected QT interval; TDM: therapeutic drug monitoring; $\uparrow:$ increased; $\downarrow$ : decreased. Italics are used in the text to reflect pharmacokinetic or pharmacodynamic mechanisms. 


\subsection{Other Anti-Infective Agents}

Use of the antimalarials chloroquine and hydroxychloroquine and the antiparasitic pentamidine can lead to a prolongation of the QT interval, possibly increasing the risk of TdP and sudden cardiac death [20]. These agents should not be combined with atypical antipsychotics with higher risk for QTc prolongation, such as amisulpride, iloperidone and ziprasidone, and iloperidone.

The possibility of PK DIs caused by these two agents has not been systematically studied but hydroxychloroquine can be a clinically relevant CYP2D6 inhibitor [110] and can increase the serum concentrations of aripiprazole, brexpiprazole, iloperidone, and risperidone. On the other hand, chloroquine does not appear to act as a CYP2D6 inhibitor [111].

A practical summary of managing DIs between antibiotics and atypical antipsychotics is reported in Table 5. 
Table 5. Practical summary of managing DIs between other anti-infective agents and atypical antipsychotics based on the authors' knowledge at the time of publication of this article.

\begin{tabular}{|c|c|c|c|}
\hline Other Anti-Infective Agents & Atypical Antipsychotics & Outcome & Actions ${ }^{1}$ \\
\hline \multirow{2}{*}{$\begin{array}{l}\text { Hydroxychloroquine is a CYP2D6 } \\
\text { inhibitor. It prolongs QTc by inhibiting the } \\
\text { heart potassium channels. }\end{array}$} & $\begin{array}{c}\text { Aripiprazole, brexpiprazole, } \\
\text { and risperidone are partly metabolized } \\
\text { by CYP2D6. }\end{array}$ & $\begin{array}{c}\uparrow \text { level of these antipsychotics after } \\
\text { adding hydroxychloroquine. } \\
\downarrow \text { level of these antipsychotics after D/C } \\
\text { hydroxychloroquine. } \\
\text { Additive effects on QTc } \\
\text { prolongation [20]. }\end{array}$ & $\begin{array}{l}\text { A. Consider alternatives. } \\
\text { B. Use TDM for better dosing these } \\
\text { antipsychotics. } \\
\text { C. In absence of TDM considering a dose } \\
\text { correction of } 0.5 \text { for these antipsychotics. } \\
\text { D. Monitor QTc. }\end{array}$ \\
\hline & $\begin{array}{l}\text { High risk QTc prolongation: amisulpride, } \\
\text { iloperidone, ziprasidone by inhibiting the } \\
\text { heart potassium channels. }\end{array}$ & $\begin{array}{c}\text { Additive effects on QTc prolongation [20]. } \\
\uparrow \text { level of iloperidone after adding } \\
\text { hydroxychloroquine. } \\
\downarrow \text { level of iloperidone after D/C } \\
\text { hydroxychloroquine. }\end{array}$ & A. Do not combine. \\
\hline $\begin{array}{l}\text { Chloroquine prolongs QTc by inhibiting } \\
\text { the heart potassium channels. } \\
\text { It may be more prone to cause psychiatric } \\
\text { symptoms than hydroxychloroquine. }\end{array}$ & $\begin{array}{l}\text { High risk QTc prolongation: amisulpride, } \\
\text { iloperidone, ziprasidone by inhibiting the } \\
\text { heart potassium channels. }\end{array}$ & $\begin{array}{l}\text { Additive effects on QTc } \\
\text { prolongation [20]. }\end{array}$ & A. Do not combine. \\
\hline
\end{tabular}

D/C: Discontinuing; DI: drug interaction; QTc: corrected QT interval; TDM: therapeutic drug monitoring; $\uparrow$ : increased; $\downarrow$ : decreased. Italics are used in the text to reflect pharmacokinetic or

pharmacodynamic mechanisms. ${ }^{1}$ A correction factor is used to modify dosing to account for DI. For example, a correction factor of 0.5 indicates that the substrate dose should be halved.

The recommendations are based on the limited information available. 


\section{Contribution of Infections}

Using information from Section 4, Tables 1-5 provides a summary of the DI of different classes of anti-infective agents. These tables ignore the fact that patients taking anti-infective agents and atypical antipsychotics frequently have active infections that may also have effects at the PK and PD mechanisms influenced by anti-infective agents and/or atypical antipsychotics. Although it is impossible to review all of these possible PK and PD effects caused by infections, Table 6 tries to provide some practical guidelines when clinicians face acute new problematic symptoms in patients taking anti-infective agents and atypical antipsychotics. They include QTc prolongation, psychosis, seizures, and symptoms compatible with an antipsychotic intoxication. Of those, we only discuss the two most lethal ADRs: QTc prolongation and pneumonia with clozapine intoxication.

Extreme QTc prolongation $>450 \mathrm{~ms}$ is usually considered a risk marker for TdP which is potentially lethal. Sudden deaths associated with TdP have an incidence in the range of $1 / 1000-1 / 10,000$ patients; therefore, most clinicians using antipsychotics may never have seen a case of TdP but, unfortunately, they continue to occur [112]. In the experience of the authors, the problem is that some psychiatrists ignore all or most DIs in their patients and this may not be lethal until the "wrong" patient is treated by them [113]. So using high doses of antipsychotics or combining them with other QTc-prolonging drugs can be non-lethal in many patients, but then cause a sudden death when multiple risk factors are accumulated in a specific patient. Moreover, a very high dose of an antipsychotic can be safe in a prior admission, but then cause a sudden death presumably explained by TdP when other factors are added in the same patient [112]. The recent COVID-19 epidemic in which many patients with serious comorbidity are treated with risky drugs helps to explain the difficulty of extrapolating from QTc prolongation to Torsades de Pointes even in situations of high-risk during infections. In this regard, a recent study included 87 Italian patients treated with 3 anti-infective agents (lopinavir/ritonavir, hydroxychloroquine, and azithromycin) with potential for QTc prolongation and provided a definition of QTc prolongation (an absolute QTc interval $\geq 500 \mathrm{~ms}$ or an increase in QTc intervals of $\geq 60 \mathrm{~ms}$ or greater compared with baseline). QTc prolongation was frequent and present in 20 patients [114]. In these 20 patients, 10 had a discontinuation of at least one of these 3 drugs and 3 died. Only 1 case of Torsades de Pointes was identified among 17 surviving patients. Clinicians expecting evidence-based medicine (EBM) approaches in this area must understand that there will never be a well-controlled prospective study that can unequivocally demonstrate that a specific drug combination is safe in a specific patient. These studies cannot accurately replicate the specific characteristics of a specific patient. DIs cannot be understood in the framework of EBM focused on average patients, but rather in the framework of personalized medicine in which each patient is different [115]. 
Table 6. New symptoms during infection when patients are co-prescribed anti-infective agents and atypical antipsychotics.

\begin{tabular}{|c|c|c|c|}
\hline Situation & Anti-Infective Agents & Atypical Antipsychotics & Actions \\
\hline $\begin{array}{c}\text { During infection: } \uparrow \text { QTc } \\
\text { Consider direct effects of infection } \\
\text { in heart. }\end{array}$ & $\begin{array}{l}\text { Risk of } \uparrow \text { QTc: macrolides, } \\
\text { fluoroquinolones, azole } \\
\text { antimycotics, some antivirals, } \\
\text { and antimalarials by inhibiting the } \\
\text { heart potassium channels. }\end{array}$ & $\begin{array}{l}\text { All can cause } \uparrow \text { QTc but highest risk for } \\
\text { amisulpride, iloperidone, and ziprasidone by } \\
\text { inhibiting the heart potassium channels. }\end{array}$ & $\begin{array}{l}\text { A. Avoid using antipsychotics with highest risk. } \\
\text { B. Be vigilant even when only one risky drug is present. Consider the } \\
\text { need for QTc monitoring. } \\
\text { C. Torsades de Pointes is very rare, but the additive risk factors are } \\
\text { family history of sudden death; personal history of syncope, } \\
\text { arrhythmias, or heart conditions; hypokalemia, hypomagnesemia, } \\
\text { and co-prescription of other medications that } \uparrow \text { QTc. Cases are more } \\
\text { frequent in females aged }>65 \text { years. } \\
\text { D. In the USA, consider the legal risk. Consider the package insert } \\
\text { warnings when combining them. }\end{array}$ \\
\hline $\begin{array}{l}\text { During infection: exacerbation of } \\
\text { psychosis in patients with } \\
\text { underlying illness or appearance } \\
\text { in patients who never } \\
\text { presented psychosis. } \\
\text { Consider brain effects of infection. }\end{array}$ & $\begin{array}{l}\text { Some anti-infective agents have } \\
\text { been associated as causal agents of } \\
\text { psychosis. }\end{array}$ & $\begin{array}{c}\text { All APs have antipsychotic efficacy by } \\
\text { inhibiting } D_{2} \text { receptors (antagonists or partial } \\
\text { agonists) at basal ganglia and/or cortex. } \\
\text { Occasionally psychotic exacerbations have } \\
\text { been suggested by aripiprazole case reports } \\
\text { by being a D2 partial agonist at basal ganglia } \\
\text { and/or cortex. }\end{array}$ & $\begin{array}{c}\text { A. Extremely complex situation. Consider all possible causal factors. } \\
\text { B. Involve other medical specialties in diagnosis. } \\
\text { C. Psychiatrist needs to carefully review PK/PD DIs of all drugs, one } \\
\text { by one, and timing of the psychosis; help other medical specialties to } \\
\text { think clearly. } \\
\text { D. If possible, change only one variable at a time. }\end{array}$ \\
\hline $\begin{array}{l}\text { Seizures during infection. Consider } \\
\text { brain effects of infection. }\end{array}$ & $\begin{array}{l}\text { Penicillins, cephalosporins, } \\
\text { imipenem, and fluoroquinolones } \\
\text { may have GABA antagonist properties. }\end{array}$ & $\begin{array}{c}\text { By } \downarrow \text { seizure threshold: } \\
\text { Highest risk: clozapine. } \\
\text { 2nd riskiest: olanzapine and quetiapine. } \\
\text { 3rd riskiest: rest of atypical antipsychotics. }\end{array}$ & $\begin{array}{c}\text { A. Extremely complex situation. } \\
\text { Consider all possible causal factors. } \\
\text { B. Involve neurologist in diagnosis. } \\
\text { C. Psychiatrist needs to carefully review PK/PD DIs of all drugs, one } \\
\text { by one, and timing of the seizure; help other medical specialties to } \\
\text { think clearly. } \\
\text { D. If possible, change only one variable at a time. }\end{array}$ \\
\hline $\begin{array}{l}\text { During infection symptoms } \\
\text { compatible with clozapine } \\
\text { intoxication (including sedation, } \\
\text { hypersalivation, myoclonus, } \\
\text { or seizure). }\end{array}$ & $\begin{array}{c}\text { Never use ciprofloxacin, enoxacin, } \\
\text { and norfloxacin which are relevant } \\
\text { inhibitors of CYP1A2. }\end{array}$ & $\begin{array}{l}\text { Presence of fever or CRP elevations are signs } \\
\text { that cytokine release may inhibit CYP1A2. }\end{array}$ & $\begin{array}{l}\text { A. Tell patient and/or family to call psychiatrist when fever or sign of } \\
\text { infection occurs. } \\
\text { B. If fever and/or CRP elevation develop, cut clozapine dose in half } \\
\text { unless clozapine TDM is immediately available. } \\
\text { C. Once clozapine intoxication occurs, cut clozapine to one-third of } \\
\text { the dose or stop completely. } \\
\text { D. If possible, monitor clozapine TDM. } \\
\text { E. Do not go back to prior clozapine dose until CRP is normal. }\end{array}$ \\
\hline
\end{tabular}


Table 6. Cont.

\begin{tabular}{|c|c|c|c|}
\hline Situation & Anti-Infective Agents & Atypical Antipsychotics & Actions \\
\hline $\begin{array}{l}\text { During infection symptoms } \\
\text { compatible with olanzapine } \\
\text { intoxication (including sedation). }\end{array}$ & $\begin{array}{c}\text { Never use ciprofloxacin, enoxacin, } \\
\text { and norfloxacin which are relevant } \\
\text { inhibitors of CYP1A2. }\end{array}$ & $\begin{array}{l}\text { Presence of fever or CRP elevations are signs } \\
\text { that cytokine release may inhibit CYP1A2. } \\
\text { Although not well-studied, elevations of } \\
\text { serum olanzapine concentrations may be } \\
\text { lower than in clozapine. }\end{array}$ & $\begin{array}{c}\text { A. If fever and/or CRP elevation develop and signs of olanzapine } \\
\text { intoxication are present, consider cutting olanzapine dose in half } \\
\text { unless olanzapine TDM is immediately available. } \\
\text { B. If possible, monitor olanzapine TDM. } \\
\text { C. Do not go back to prior olanzapine dose until CRP is normal. }\end{array}$ \\
\hline $\begin{array}{l}\text { During infection symptoms } \\
\text { compatible with antipsychotic } \\
\text { intoxication and patient on } \\
\text { antipsychotic dependent on } \\
\text { CYP3A4. Cariprazine, lurasidone } \\
\text { and quetiapine are mainly } \\
\text { metabolized by CYP3A4. } \\
\text { Aripiprazole, brexpiprazole, } \\
\text { iloperidone and risperidone are } \\
\text { partly metabolized by CYP3A4. }\end{array}$ & $\begin{array}{l}\text { Never use erythromycin, } \\
\text { clarithromycin, } \\
\text { and troleandomycin which are } \\
\text { relevant inhibitors of CYP } 3 A 4 \text {. }\end{array}$ & $\begin{array}{l}\text { Presence of fever or CRP elevations are signs } \\
\text { that cytokine release may inhibit CYP3A4. } \\
\text { Although not well-studied, elevations of } \\
\text { serum concentrations of these antipsychotics } \\
\text { may be lower than in clozapine. }\end{array}$ & $\begin{array}{l}\text { A. If fever and/or CRP elevation develop and signs of antipsychotic } \\
\text { intoxication are present, consider decreasing the dose unless TDM is } \\
\text { immediately available. } \\
\text { B. If possible, monitor TDM. } \\
\text { C. Do not go back to prior antipsychotic dose until CRP is normal. }\end{array}$ \\
\hline
\end{tabular}

CRP: c-reactive protein; D/C: Discontinuing; DI: drug interaction; PK: pharmacokinetic; PD: pharmacodynamic; QTc: corrected QT interval; TDM: therapeutic drug monitoring; $\uparrow:$ increased; $\downarrow$ : decreased. Italics are used in the text to reflect pharmacokinetic or pharmacodynamic mechanisms. 
Severe infections are usually manifested with signs of generalized inflammation including fever and serum c-reactive protein (CRP) elevations secondary to the cytokines released. The literature is accumulating information that the cytokines can inhibit several CYPs [116]. There is definitive information that inflammation can increase serum clozapine concentrations [32,117]. More limited is the information on olanzapine, which is also metabolized by CYP1A2 [118], and in the antipsychotics dependent on CYP3A4 [119,120]. This peculiar DI, caused by inflammation-released cytokines, may be relevant for clozapine use. Clozapine probably has the narrowest therapeutic index of all atypical antipsychotics [121]. This may explain why in a study of the ADRs reported to the FDA, clozapine ranked as the third most lethal drug with 3277 deaths [122]. In a review of clozapine ADRs reported to an international database by all national drug agencies, pneumonia was associated with 2077 deaths versus 1149 sudden deaths or 550 deaths associated with agranulocytosis [123]. In this database, pneumonia was more closely associated to clozapine than other antipsychotics [124] but, according to a study in a national registry database, the variables associated with treatment-refractoriness may be more important contributors to pneumonia than clozapine [125]. The lethality of pneumonia in clozapine patients is probably due to a combination of pneumonia and the associated clozapine intoxication [126]. Decreasing the clozapine dosage during infections with systemic inflammation may be a good idea [52]. Cases of clozapine intoxication are starting to be described during pneumonia associated with the COVID-19 virus [127].

\section{Conclusions}

After a comprehensive search of the literature, Section 4 describes the limited information published on DIs between atypical antipsychotics and anti-infective agents. The reader should remember that the lack of published studies or case reports does not preclude the occurrence of DIs in their patients. Thus, based on our prior articles of DIs of atypical antipsychotics [3,4,8,29,121] and our current understanding of PK and PD mechanisms, we have developed practical recommendations for clinicians summarized in Table 1 for antibiotic DIs, Table 2 for antitubercular DIs, Table 3 for antifungal DIs, Table 4 for antiviral DIs, and Table 5 for other anti-infective DIs. We have never in prior articles used a table such as Table 6 interpreting DIs in the complexity of clinical practice. DIs between atypical antipsychotics and anti-infective agents do not happen in a laboratory but in a live patient who also has an infection that may influence the PK and PD mechanisms of all administered drugs. These tables reflect the currently available literature and our current knowledge of the field and will need to be updated as new DI information becomes available allowing us to provide better practical recommendations. We remind the reader to look for future updates of this article and others focused on atypical antipsychotic DIs. Hopefully, the reader will agree with us that this article is much better and more practical than our first attempt to write about DIs in atypical antipsychotics 13 years ago [8]. Anyway, with all of its limitations, this is the only published review focused on the DIs between atypical antipsychotics and anti-infective agents. Finally, we encourage researchers to publish new studies on DIs in atypical antipsychotics and anti-infective agents and that, in the absence of these studies, case reports published by clinicians may be the only way to move the field forward.

Author Contributions: Conceptualization, E.S. and J.d.L.; methodology, E.S. and J.d.L.; resource, M.A.B. and G.C.; writing-original draft preparation, E.S. and J.d.L.; writing-review and editing, E.S. and J.d.L.; supervision, E.S. All authors have read and agreed to the published version of the manuscript.

Funding: This research was not supported by any funding source.

Acknowledgments: The authors acknowledge Lorraine Maw, M.A., at the Mental Health Research Center at Eastern State Hospital, Lexington, KY, USA, who helped in editing this article

Conflicts of Interest: In the past few years, Edoardo Spina has participated in speakers/advisory boards and lectured supported by Angelini, ArcaPharma, Janssen Pharmaceuticals, Lundbeck and Otsuka. Jose de Leon personally develops his presentations for lecturing, has never lectured using any pharmaceutical or pharmacogenetic company presentations, and has never been a consultant for pharmacogenetic or pharmaceutical companies. In the past, Jose de Leon received researcher-initiated grants from Eli Lilly (one ended in 2003 and the other, as co-investigator, ended in 2007); from Roche Molecular Systems, Inc. (ended in 2007); and, in a collaboration 
with Genomas, Inc., from the NIH Small Business Innovation Research program (ended in 2010). He has been on the advisory boards of Bristol-Myers Squibb (2003/04) and AstraZeneca (2003). Roche Molecular Systems supported one of his educational presentations, which was published in a peer-reviewed journal (2005). His lectures were supported once by Sandoz (1997), twice by Lundbeck (1999 and 1999), twice by Pfizer (2001 and 2001), three times by Eli Lilly (2003, 2006, and 2006), twice by Janssen (2000 and 2006), once by Bristol-Myers Squibb (2006), and seven times by Roche Molecular Systems, Inc. (once in 2005 and six times in 2006). Maria Antonietta Barbieri and Giuseppe Cicala have no conflict of interest.

\section{References}

1. Spina, E.; Italiano, D. Drug interactions. In Treatment of Epilepsy; Wiley-Blackwell Publishing Ltd.: Oxford, UK, 2015; pp. 344-359.

2. Stahl, S.M. Antipsychotic agents. In Stahl's Essential Psychopharmacology; Cambridge University Press: New York, NY, USA, 2013; pp. 129-236.

3. De Leon, J.; Santoro, V.; D'Arrigo, C.; Spina, E. Interactions between antiepileptics and second-generation antipsychotics. Expert Opin. Drug Metab. Toxicol. 2012, 8, 311-334. [CrossRef] [PubMed]

4. Spina, E.; De Leon, J. Clinically relevant interactions between newer antidepressants and second-generation antipsychotics. Expert Opin. Drug Metab. Toxicol. 2014, 10, 721-746. [CrossRef] [PubMed]

5. Gillum, J.G.; Israel, D.S.; Polk, R.E. Pharmacokinetic Drug Interactions with Antimicrobial Agents. Clin. Pharmacokinet. 1993, 25, 450-482. [CrossRef] [PubMed]

6. Gregg, C.R. Drug interactions and anti-infective therapies. Am. J. Med. 1999, 106, 227-237. [CrossRef]

7. Barcia, E.; Negro, S. Interactions of anti-infectives: A review. Chemotherapy 2005, 51, 197-199. [CrossRef] [PubMed]

8. Spina, E.; De Leon, J. Metabolic drug interactions with newer antipsychotics: A comparative review. Basic Clin. Pharmacol. Toxicol. 2007, 100, 4-22. [CrossRef] [PubMed]

9. Kennedy, W.K.; Jann, M.W.; Kutscher, E.C. Clinically significant drug interactions with atypical antipsychotics. CNS Drugs 2013, 27, 1021-1048. [CrossRef]

10. Westphal, J.F. Macrolide-Induced clinically relevant drug interactions with cytochrome P-450A (CYP) 3A4: An update focused on clarithromycin, azithromycin and dirithromycin. Br. J. Clin. Pharmacol. 2000, 29, 1507-1514. [CrossRef]

11. Fuhr, U.; Anders, E.M.; Mahr, G.; Sorgel, F.; Staib, A.H. Inhibitory potency of quinolone antibacterial agents against cytochrome P450IA2 activity in vivo and in vitro. Antimicrob. Agents Chemother. 1992, 36, 942-948. [CrossRef]

12. Brüggemann, R.J.M.; Alffenaar, J.W.C.; Blijlevens, N.M.A.; Billaud, E.M.; Kosterink, J.G.W.; Verweij, P.E.; Burger, D.M. Clinical relevance of the pharmacokinetic interactions of azole antifungal drugs with other coadministered agents. Clin. Infect. Dis. 2009, 48, 1441-1458. [CrossRef]

13. Yew, W.W. Clinically significant interactions with drugs used in the treatment of tuberculosis. Drug Saf. 2002, 25, 111-113. [CrossRef] [PubMed]

14. Hughes, C.A.; Tseng, A.; Cooper, R. Managing drug interactions in HIV-infected adults with comorbid illness. CMAJ 2015, 187, 36-43. [CrossRef] [PubMed]

15. Baciewicz, A.M.; Chrisman, C.R.; Finch, C.K.; Self, T.H. Update on rifampin, rifabutin, and rifapentine drug interactions. Curr. Med. Res. Opin. 2013, 29, 1-12. [CrossRef]

16. Moons, T.; De Roo, M.; Claes, S.; Dom, G. Relationship between P-glycoprotein and second-generation antipsychotics. Pharmacogenomics 2011, 12, 1193-1211. [CrossRef] [PubMed]

17. Akamine, Y.; Yasui-Furukori, N.; Ieiri, I.; Uno, T. Psychotropic drug-drug interactions involving P-glycoprotein. CNS Drugs 2012, 26, 959-973. [CrossRef]

18. Hasnain, M.; Vieweg, W.V.R. QTc interval prolongation and torsade de pointes associated with second-generation antipsychotics and antidepressants: A comprehensive review. CNS Drugs 2014, 28, 887-920. [CrossRef]

19. Huhn, M.; Nikolakopoulou, A.; Schneider-Thoma, J.; Krause, M.; Samara, M.; Peter, N.; Arndt, T.; Bäckers, L.; Rothe, P.; Cipriani, A.; et al. Comparative efficacy and tolerability of 32 oral antipsychotics for the acute treatment of adults with multi-episode schizophrenia: A systematic review and network meta-analysis. Lancet 2019, 394, 939-951. [CrossRef]

20. Mason, J.W. Antimicrobials and QT prolongation. J. Antimicrob. Chemother. 2017, 72, 1272-1274. [CrossRef] 
21. Newcomer, J.W. Second-generation (atypical) antipsychotics and metabolic effects: A comprehensive literature review. CNS Drugs 2005, 19 (Suppl. S1), 1-93. [CrossRef]

22. Pillinger, T.; McCutcheon, R.A.; Vano, L.; Mizuno, Y.; Arumuham, A.; Hindley, G.; Beck, K.; Natesan, S.; Efthimiou, O.; Cipriani, A.; et al. Comparative effects of 18 antipsychotics on metabolic function in patients with schizophrenia, predictors of metabolic dysregulation, and association with psychopathology: A systematic review and network meta-analysis. Lancet Psychiatry 2020, 7, 64-77. [CrossRef]

23. Samaras, K.; Wand, H.; Matthew, L.; Emery, S.; Cooper, D.; Carr, A. Prevalence of metabolic syndrome in HIV-infected patients receiving highly active antiretroviral therapy using International Diabetes Foundation and Adult Treatment Panel III criteria: Associations with insulin resistance, disturbed body fat compartmental. Diabetes Care 2007, 30, 113-119. [CrossRef] [PubMed]

24. Lagathu, C.; Béréziat, V.; Gorwood, J.; Fellahi, S.; Bastard, J.P.; Vigouroux, C.; Boccara, F.; Capeau, J. Metabolic complications affecting adipose tissue, lipid and glucose metabolism associated with HIV antiretroviral treatment. Expert Opin. Drug Saf. 2019, 18, 829-840. [CrossRef] [PubMed]

25. Zaid, D.; Greenman, Y. Human immunodeficiency virus infection and the endocrine system. Endocrinol. Metab. 2019, 34, 95-105. [CrossRef] [PubMed]

26. Zareifopoulos, N.; Panayiotakopoulos, G. Neuropsychiatric Effects of Antimicrobial Agents. Clin. Drug Investig. 2017, 37, 423-437. [CrossRef]

27. Bangert, M.K.; Hasbun, R. Neurological and Psychiatric Adverse Effects of Antimicrobials. CNS Drugs 2019, 33, 727-753. [CrossRef]

28. Wanleenuwat, P.; Suntharampillai, N.; Iwanowski, P. Antibiotic-induced epileptic seizures: Mechanisms of action and clinical considerations. Seizure 2020, 81, 167-174. [CrossRef]

29. Spina, E.; Leon, J. de Potentially Clinically Relevant Pharmacodynamic Interactions Between Antiepileptic Drugs and Psychotropic Drugs: An Update. Curr. Pharm. Des. 2017, 23, 5625-5638. [CrossRef]

30. Funderburg, L.G.; Vertrees, J.E.; True, J.E.; Miller, A.L. Seizure following addition of erythromycin to clozapine treatment. Am. J. Psychiatry 1994, 151, 1840-1841. [CrossRef]

31. Cohen, L.G.; Chesley, S.; Eugenio, L.; Flood, J.G.; Fisch, J.; Goff, D.C. Erythromycin-induced clozapine toxic reaction. Arch. Intern. Med. 1996, 156, 675-677. [CrossRef]

32. De Leon, J. Respiratory infections rather than antibiotics may increase clozapine levels: A critical review of the literature. J. Clin. Psychiatry 2004, 65, 1144-1145. [CrossRef]

33. Hägg, S.; Spigset, O.; Mjörndal, T.; Granberg, K.; Persbo-Lundqvist, G.; Dahlqvist, R. Absence of interaction between erythromycin and a single dose of clozapine. Eur. J. Clin. Pharmacol. 1999, 55, 221-226. [CrossRef] [PubMed]

34. Lane, H.Y.; Jann, M.W.; Chang, Y.C.; Chiu, C.C.; Huang, M.C.; Lee, S.H.; Chang, W.H. Repeated ingestion of grapefruit juice does not alter clozapine's steady-state plasma levels, effectiveness, and tolerability. J. Clin. Psychiatry 2001, 62, 812-817. [CrossRef] [PubMed]

35. Li, K.Y.; Li, X.; Cheng, Z.N.; Zhang, B.K.; Peng, W.X.; Li, H. De Effect of erythromycin on metabolism of quetiapine in Chinese suffering from schizophrenia. Eur. J. Clin. Pharmacol. 2005, 60, 791-795. [CrossRef] [PubMed]

36. Schulz-Du Bois, C.; Schulz-Du Bois, A.C.; Bewig, B.; Gerstner, I.; Aldenhoff, J.B.; Cascorbi, I.; Ufer, M. Major increase of quetiapine steady-state plasma concentration following co-administration of clarithromycin: Confirmation of the pharmacokinetic interaction potential of quetiapine. Pharmacopsychiatry 2008, 41, 258-259. [CrossRef] [PubMed]

37. Albert, R.K.; Schuller, J.L. Macrolide antibiotics and the risk of cardiac arrhythmias. Am. J. Respir. Crit. Care Med. 2014, 189, 1173-1180. [CrossRef] [PubMed]

38. Gbinigie, I.I.; Lasserson, D. Clarithromycin-induced akathisia: A class effect of macrolides? BMJ Case Rep. 2016, 2016, bcr2016217421. [CrossRef]

39. Sachdeva, A.; Rathee, R. Akathisia with Erythromycin: Induced or precipitated? Saudi Pharm. J. 2015, 23, 541-543. [CrossRef]

40. Markowitz, J.S.; Gill, H.S.; Devane, C.L.; Mintzer, J.E. Fluoroquinolone inhibition of clozapine metabolism. Am. J. Psychiatry 1997, 154, 881. [CrossRef]

41. Raaska, K.; Neuvonen, P.J. Ciprofloxacin increases serum clozapine and N-desmethylclozapine: A study in patients with schizophrenia. Eur. J. Clin. Pharmacol. 2000, 56, 585-589. [CrossRef] 
42. Gex-Fabry, M.; Balant-Gorgia, A.E.; Balant, L.P. Therapeutic drug monitoring databases for postmarketing surveillance of drug-drug interactions. Drug Saf. 2001, 24, 947-959. [CrossRef]

43. Brownlowe, K.; Sola, C. Clozapine toxicity in smoking cessation and with ciprofloxacin. Psychosomatics 2008, 49, 176. [CrossRef] [PubMed]

44. Brouwers, E.E.M.; Söhne, M.; Kuipers, S.; Van Gorp, E.C.M.; Schellens, J.H.M.; Koks, C.H.W.; Beijnen, J.H.; Huitema, A.D.R. Ciprofloxacin strongly inhibits clozapine metabolism: Two case reports. Clin. Drug Investig. 2009, 29, 59-63. [CrossRef]

45. Meyer, J.M.; Proctor, G.; Cummings, M.A.; Dardashti, L.J.; Stahl, S.M. Ciprofloxacin and Clozapine: A Potentially Fatal but Underappreciated Interaction. Case Rep. Psychiatry 2016, 2016, 1-7. [CrossRef] [PubMed]

46. Sandson, N.B.; Cozza, K.L.; Armstrong, S.C.; Eckermann, G.; Fischer, B.A.; Phillips, B. Clozapine case series. Psychosomatics 2007, 48, 170-175. [CrossRef]

47. Sambhi, R.S.; Puri, R.; Jones, G. Interaction of clozapine and ciprofloxacin: A case report. Eur. J. Clin. Pharmacol. 2007, 63, 895-896. [CrossRef]

48. Markowitz, J.S.; Devane, C.L. Suspected ciprofloxacin inhibition of olanzapine resulting in increased plasma concentration. J. Clin. Psychopharmacol. 1999, 19, 289-291. [CrossRef]

49. Ridout, K.K.; Ridout, S.J.; Pirnie, L.F.; Puttichanda, S.P. Sudden-onset dystonia in a patient taking asenapine: Interaction between ciprofloxacin and asenapine metabolism. Am. J. Psychiatry 2015, 172, 1162-1163. [CrossRef]

50. Kinzig-Schippers, M.; Fuhr, U.; Zaigler, M.; Dammeyer, J.; Rüsing, G.; Labedzki, A.; Bulitta, J.; Sörgel, F. Interaction of pefloxacin and enoxacin with the human cytochrome P450 enzyme CYP1A2. Clin. Pharmacol. Ther. 1999, 65, 262-274. [CrossRef]

51. Zhang, L.; Wei, M.J.; Zhao, C.Y.; Qi, H.M. Determination of the inhibitory potential of 6 fuoroquinolones on CYP1A2 and CYP2C9 in human liver microsomes. Acta Pharmacol. Sin. 2008, 29, 1507-1514. [CrossRef]

52. Ruan, C.J.; Zang, Y.N.; Cheng, Y.H.; Wang, C.Y.; De Leon, J. Around 3\% of 1,300 Levels Were Elevated during Infections in a Retrospective Review of 131 Beijing Hospital In-Patients with More than 24,000 Days of Clozapine Treatment. Psychother. Psychosom. 2020, 89, 255-257. [CrossRef]

53. Briasoulis, A.; Agarwal, V.; Pierce, W.J. QT prolongation and Torsade de pointes induced by fluoroquinolones: Infrequent side effects from commonly used medications. Cardiology 2011, 120, 103-110. [CrossRef] [PubMed]

54. Letsas, K.P.; Sideris, A.; Kounas, S.P.; Efremidis, M.; Korantzopoulos, P.; Kardaras, F. Drug-induced QT interval prolongation after ciprofloxacin administration in a patient receiving olanzapine. Int. J. Cardiol. 2006, 109, 273-274. [CrossRef] [PubMed]

55. Xiang, Y.Q.; Zheng, W.; Wang, S.B.; Yang, X.H.; Cai, D.B.; Ng, C.H.; Ungvari, G.S.; Kelly, D.L.; Xu, W.Y.; Xiang, Y.T. Adjunctive minocycline for schizophrenia: A meta-analysis of randomized controlled trials. Eur. Neuropsychopharmacol. 2017, 27, 8-18. [CrossRef] [PubMed]

56. Wehring, H.J.; Elsobky, T.; McEvoy, J.P.; Vyas, G.; Richardson, C.M.; McMahon, R.P.; DiPaula, B.A.; Liu, F.; Sullivan, K.; Buchanan, R.W.; et al. Adjunctive Minocycline in Clozapine-Treated Patients with Schizophrenia: Analyzing the Effects of Minocycline on Clozapine Plasma Levels. Psychiatr. Q. 2018, 89, 73-80. [CrossRef]

57. Grün, B.; Kiessling, M.K.; Burhenne, J.; Riedel, K.D.; Weiss, J.; Rauch, G.; Haefeli, W.E.; Czock, D. Trimethoprim-metformin interaction and its genetic modulation by OCT2 and MATE1 transporters. $\mathrm{Br}$. J. Clin. Pharmacol. 2013, 76, 787-796. [CrossRef]

58. Thyssen, A.; Cleton, A.; Talluri, K.; Leempoels, J.; Janssens, L.; Boom, S.; Eerdekens, M. No pharmacokinetic interaction between paliperidone extended-release tablets and trimethoprim in healthy subjects. Hum. Psychopharmacol. 2009, 24, 532-539. [CrossRef]

59. Schoretsanitis, G.; Spina, E.; Hiemke, C.; De Leon, J. A systematic review and combined analysis of therapeutic drug monitoring studies for long-acting paliperidone. Expert Rev. Clin. Pharmacol. 2018, 11, 1237-1253. [CrossRef]

60. Csík, V.; Molnár, J. Possible Adverse Interaction between Clozapine and Ampicillin in an Adolescent with Schizophrenia. J. Child Adolesc. Psychopharmacol. 1994, 4, 123-128. [CrossRef]

61. Niemi, M.; Backman, J.T.; Fromm, M.F.; Neuvonen, P.J.; Kivistö, K.T. Pharmacokinetic interactions with rifampicin: Clinical relevance. Clin. Pharmacokinet. 2003, 42, 819-850. [CrossRef] 
62. Reitman, M.L.; Chu, X.; Cai, X.; Yabut, J.; Venkatasubramanian, R.; Zajic, S.; Stone, J.A.; Ding, Y.; Witter, R.; Gibson, C.; et al. Rifampin's acute inhibitory and chronic inductive drug interactions: Experimental and model-based approaches to drug-drug interaction trial design. Clin. Pharmacol. Ther. 2011, 89, 234-242. [CrossRef]

63. Joos, A.A.B.; Frank, U.G.; Kaschka, W.P. Pharmacokinetic interaction of clozapine and rifampicin in a forensic patient with an atypical mycobacterial infection. J. Clin. Psychopharmacol. 1998, 18, 83-85. [CrossRef] [PubMed]

64. Peritogiannis, V.; Pappas, D.; Antoniou, K.; Hyphantis, T.; Mavreas, V. Clozapine-rifampicin interaction in a patient with pulmonary tuberculosis. Gen. Hosp. Psychiatry 2007, 29, 281-282. [CrossRef] [PubMed]

65. Parker, C. Prescribing clozapine and rifampicin: Clinical impact of their interaction. BJPsych Bull. 2016, 40, 153-155. [CrossRef] [PubMed]

66. Mahatthanatrakul, W.; Nontaput, T.; Ridtitid, W.; Wongnawa, M.; Sunbhanich, M. Rifampin, a cytochrome P450 3A inducer, decreases plasma concentrations of antipsychotic risperidone in healthy volunteers. J. Clin. Pharm. Ther. 2007, 32, 161-167. [CrossRef] [PubMed]

67. Kim, K.A.; Park, P.W.; Liu, K.H.; Kim, K.B.; Lee, H.J.; Shin, J.G.; Park, J.Y. Effect of rifampin, an inducer of CYP3A and P-glycoprotein, on the pharmacokinetics of risperidone. J. Clin. Pharmacol. 2008, 48, 66-72. [CrossRef] [PubMed]

68. Chiu, Y.Y.; Ereshefsky, L.; Preskorn, S.H.; Poola, N.; Loebel, A. Lurasidone drug-drug interaction studies: A comprehensive review. Drug Metabol. Drug Interact. 2014, 29, 191-202. [CrossRef] [PubMed]

69. Angelini, M.C.; MacCormack-Gagnon, J.; Dizio, S. Increase in plasma levels of clozapine after addition of isoniazid. J. Clin. Psychopharmacol. 2009, 29, 190-191. [CrossRef]

70. Desta, Z.; Soukhova, N.V.; Flockhart, D.A. Inhibition of cytochrome P450 (CYP450) isoforms by isoniazid: Potent inhibition of CYP2C19 and CYP3A. Antimicrob. Agents Chemother. 2001, 45, 382-392. [CrossRef]

71. Dvorak, Z. Drug-drug interactions by azole antifungals: Beyond a dogma of CYP3A4 enzyme activity inhibition. Toxicol. Lett. 2011, 202, 129-132. [CrossRef]

72. DeVane, C.L.; Nemeroff, C.B. Clinical pharmacokinetics of quetiapine: An atypical antipsychotic. Clin. Pharmacokinet. 2001, 40, 509-522. [CrossRef]

73. Grimm, S.W.; Richtand, N.M.; Winter, H.R.; Stams, K.R.; Reele, S.B. Effects of cytochrome P450 3A modulators ketoconazole and carbamazepine on quetiapine pharmacokinetics. Br. J. Clin. Pharmacol. 2006, 61, 58-69. [CrossRef] [PubMed]

74. Mahatthanatrakul, W.; Sriwiriyajan, S.; Ridtitid, W.; Boonleang, J.; Wongnawa, M.; Rujimamahasan, N.; Pipatrattanaseree, W. Effect of cytochrome P450 3A4 inhibitor ketoconazole on risperidone pharmacokinetics in healthy volunteers. J. Clin. Pharm. Ther. 2012, 37, 221-225. [CrossRef] [PubMed]

75. Miceli, J.J.; Smith, M.; Robarge, L.; Morse, T.; Laurent, A. The effects of ketoconazole on ziprasidone pharmacokinetics-A placebo-controlled crossover study in healthy volunteers. Br. J. Clin. Pharmacol. 2000, 49, 71-76. [CrossRef] [PubMed]

76. Raaska, K.; Neuvonen, P.J. Serum concentrations of clozapine and N-desmethylclozapine are unaffected by the potent CYP3A4 inhibitor itraconazole. Eur. J. Clin. Pharmacol. 1998, 54, 167-170. [CrossRef]

77. Lane, H.Y.; Chiu, C.C.; Kazmi, Y.; Desai, H.; Francis Lam, Y.W.; Jann, M.W.; Chang, W.H. Lack of CYP3A4 inhibition by grapefruit juice and ketoconazole upon clozapine administration in vivo. Drug Metabol. Drug Interact. 2001, 18, 263-278. [CrossRef]

78. Jung, S.M.; Kim, K.A.; Cho, H.K.; Jung, I.G.; Park, P.W.; Byun, W.T.; Park, J.Y. Cytochrome P450 3A inhibitor itraconazole affects plasma concentrations of risperidone and 9-hydroxyrisperidone in schizophrenic patients. Clin. Pharmacol. Ther. 2005, 78, 520-528. [CrossRef]

79. Kubo, M.; Koue, T.; Inaba, A.; Takeda, H.; Maune, H.; Fukuda, T.; Azuma, J. Influence of itraconazole co-administration and CYP2D6 genotype on the pharmacokinetics of the new antipsychotic ARIPIPRAZOLE. Drug Metab. Pharmacokinet. 2005, 20, 55-64. [CrossRef]

80. Greenblatt, D.J.; Harmatz, J.S.; Ryan, M.J.; Chow, C.R. Sustained Impairment of Lurasidone Clearance after Discontinuation of Posaconazole: Impact of Obesity, and Implications for Patient Safety. J. Clin. Psychopharmacol. 2018, 38, 289-295. [CrossRef]

81. Salem, M.; Reichlin, T.; Fasel, D.; Leuppi-Taegtmeyer, A. Torsade de pointes and systemic azole antifungal agents: Analysis of global spontaneous safety reports. Glob. Cardiol. Sci. Pract. 2017, 2017, 11. [CrossRef] 
82. Harrigan, E.P.; Miceli, J.J.; Anziano, R.; Watsky, E.; Reeves, K.R.; Cutler, N.R.; Sramek, J.; Shiovitz, T.; Middle, M. A Randomized Evaluation of the Effects of Six Antipsychotic Agents on QTc, In the Absence and Presence of Metabolic Inhibition. J. Clin. Psychopharmacol. 2004, 24, 62-69. [CrossRef]

83. Potkin, S.G.; Preskorn, S.; Hochfeld, M.; Meng, X. A thorough QTc study of 3 doses of iloperidone including metabolic inhibition via CYP2D6 and/or CYP3A4 and a comparison to quetiapine and ziprasidone. J. Clin. Psychopharmacol. 2013, 33, 3-10. [CrossRef] [PubMed]

84. Hughes, E.; Bassi, S.; Gilbody, S.; Bland, M.; Martin, F. Prevalence of HIV, hepatitis B, and hepatitis C in people with severe mental illness: A systematic review and meta-analysis. Lancet Psychiatry 2016, 3, 40-48. [CrossRef]

85. Hill, L.; Lee, K.C. Pharmacotherapy considerations in patients with HIV and psychiatric disorders: Focus on antidepressants and antipsychotics. Ann. Pharmacother. 2013, 47, 75-89. [CrossRef] [PubMed]

86. Goodlet, K.J.; Zmarlicka, M.T.; Peckham, A.M. Drug-drug interactions and clinical considerations with co-administration of antiretrovirals and psychotropic drugs. CNS Spectr. 2019, 24, 287-312. [CrossRef] [PubMed]

87. Kelly, D.V.; Béïque, L.C.; Bowmer, M.I. Extrapyramidal symptoms with ritonavir/indinavir plus risperidone. Ann. Pharmacother. 2002, 36, 827-830. [CrossRef] [PubMed]

88. Jover, F.; Cuadrado, J.M.; Andreu, L.; Merino, J. Reversible coma caused by risperidone-ritonavir interaction. Clin. Neuropharmacol. 2002, 25, 251-253. [CrossRef] [PubMed]

89. Lee, S.I.; Klesmer, J.; Hirsch, B.E. Neuroleptic malignant syndrome associated with use of risperidone, ritonavir, and indinavir: A case report. Psychosomatics 2000, 41, 453-454. [CrossRef]

90. Gonzalez, L.S.; Kothari, K.; Kasle, D.A. Three cases of late onset angioedema in nursing home human immunodeficiency virus patients on ritonavir and risperidone. J. Clin. Psychopharmacol. 2016, 36, 95-97. [CrossRef]

91. Pollack, T.M.; McCoy, C.; Stead, W. Clinically significant adverse events from a drug interaction between quetiapine and atazanavir-ritonavir in two patients. Pharmacotherapy 2009, 29, 1386-1391. [CrossRef]

92. Hantson, P.; Fazio, V.; Wallemacq, P. Toxicokinetic Interaction Between Quetiapine and Antiretroviral Therapy Following Quetiapine Overdose. Drug Metab. Lett. 2010, 4, 7-8. [CrossRef]

93. Pollak, P.T.; Zbuk, K. Quetiapine fumarate overdose: Clinical and pharmacokinetic lessons from extreme conditions. Clin. Pharmacol. Ther. 2000, 68, 92-97. [CrossRef] [PubMed]

94. Aung, G.L.; O’Brien, J.G.; Tien, P.G.; Kawamoto, L.S. Increased aripiprazole concentrations in an HIV-positive male concurrently taking duloxetine, darunavir, and ritonavir. Ann. Pharmacother. 2010, 44, 1850-1854. [CrossRef] [PubMed]

95. Hahn, M.; Roll, S.C. Dosing Recommendations of Aripiprazole Depot with Strong Cytochrome P450 3A4 Inhibitors: A Relapse Risk. Drug Saf. Case Rep. 2016, 3, 5. [CrossRef] [PubMed]

96. Naccarato, M.; Hall, E.; Wai, A.; Ostrowski, M.; Carvalhal, A. A case of a probable drug interaction between lurasidone and atazanavir-based antiretroviral therapy. Antivir. Ther. 2016, 21, 735-738. [CrossRef]

97. Penzak, S.R.; Hon, Y.Y.; Lawhorn, W.D.; Shirley, K.L.; Spratlin, V.; Jann, M.W. Influence of ritonavir on olanzapine pharmacokinetics in healthy volunteers. J. Clin. Psychopharmacol. 2002, 22, 366-370. [CrossRef]

98. Jacobs, B.S.; Colbers, A.P.H.; Velthoven-Graafland, K.; Schouwenberg, B.J.J.W.; Burger, D.M. Effect of fosamprenavir/ritonavir on the pharmacokinetics of single-dose olanzapine in healthy volunteers. Int. J. Antimicrob. Agents 2014, 44, 173-177. [CrossRef]

99. Vergara-Rodriguez, P.; Vibhakar, S.; Watts, J. Metabolic syndrome and associated cardiovascular risk factors in the treatment of persons with human immunodeficiency virus and severe mental illness. Pharmacol. Ther. 2009, 124, 269-278. [CrossRef]

100. Aberg, J.A.; Tebas, P.; Overton, E.T.; Gupta, S.K.; Sax, P.E.; Landay, A.; Falcon, R.; Ryan, R.; De La Rosa, G. Metabolic effects of darunavir/ritonavir versus atazanavir/ritonavir in treatment-naive, HIV Type 1-infected subjects over 48 weeks. AIDS Res. Hum. Retrovir. 2012, 28, 1184-1195. [CrossRef]

101. Ferrara, M.; Umlauf, A.; Sanders, C.; Meyer, J.M.; Allen McCutchan, J.; Duarte, N.; Hampton Atkinson, J.; Grant, I.; Ellis, R.J. The concomitant use of second-generation antipsychotics and long-term antiretroviral therapy may be associated with increased cardiovascular risk. Psychiatry Res. 2014, 218, 201-208. [CrossRef]

102. Anson, B.D.; Weaver, J.G.R.; Ackerman, M.J.; Akinsete, O.; Henry, K.; January, C.T.; Badley, A.D. Blockade of HERG channels by HIV protease inhibitors. Lancet 2005, 365, 682-686. [CrossRef] 
103. Nejad, S.H.; Gandhi, R.T.; Freudenreich, O. Clozapine Use in HIV-Infected Schizophrenia Patients: A Case-Based Discussion and Review. Psychosomatics 2009, 50, 626-632. [CrossRef]

104. Foster, R.; Olajide, D.; Everall, P. Antiretroviral therapy-induced psychosis: Case report and brief review of the literature. HIV Med. 2003, 4, 139-144. [CrossRef] [PubMed]

105. Arendt, G.; De Nocker, D.; Von Giesen, H.J.; Nolting, T. Neuropsychiatric side effects of efavirenz therapy. Expert Opin. Drug Saf. 2007, 6, 147-154. [CrossRef] [PubMed]

106. Abers, M.S.; Shandera, W.X.; Kass, J.S. Neurological and psychiatric adverse effects of antiretroviral drugs. CNS Drugs 2014, 28, 131-145. [CrossRef] [PubMed]

107. Garrison, K.L.; German, P.; Mogalian, E.; Mathias, A. The drug-drug interaction potential of antiviral agents for the treatment of chronic hepatitis C infection. Drug Metab. Dispos. 2018, 46, 1212-1225. [CrossRef] [PubMed]

108. Smolders, E.J.; De Kanter, C.T.M.M.; De Knegt, R.J.; Van der Valk, M.; Drenth, J.P.H.; Burger, D.M. Drug-Drug Interactions Between Direct-Acting Antivirals and Psychoactive Medications. Clin. Pharmacokinet. 2016, 55, 1471-1494. [CrossRef]

109. Roncero, C.; Villegas, J.L.; Martínez-Rebollar, M.; Buti, M. The pharmacological interactions between direct-acting antivirals for the treatment of chronic hepatitis c and psychotropic drugs. Expert Rev. Clin. Pharmacol. 2018, 11, 999-1030. [CrossRef]

110. Somer, M.; Kallio, J.; Pesonen, U.; Pyykkö, K.; Huupponen, R.; Scheinin, M. Influence of hydroxychloroquine on the bioavailability of oral metoprolol. Br. J. Clin. Pharmacol. 2000, 49, 549-554. [CrossRef]

111. Masimirembwa, C.M.; Gustafsson, L.L.; Dahl, M.L.; Abdi, Y.A.; Hasler, J.A. Lack of effect of chloroquine on the debrisoquine (CYP2D6) and S-mephenytoin (CYP2C19) hydroxylation phenotypes. Br. J. Clin. Pharmacol. 1996, 41, 344-346. [CrossRef]

112. Wahidi, N.; Johnson, K.M.; Brenzel, A.; Leon, J. de Two Sudden and Unexpected Deaths of Patients with Schizophrenia Associated with Intramuscular Injections of Antipsychotics and Practice Guidelines to Limit the Use of High Doses of Intramuscular Antipsychotics. Case Rep. Psychiatry 2016, 2016, 1-14. [CrossRef]

113. De Leon, J. Why Do You Keep Telling Me That Drug-Drug Interactions Are Important in Psychopharmacology When i Do Not See Them in My Clinical Practice?: My Failure to Convince Clinicians. J. Clin. Psychopharmacol. 2019, 39, 1-4. [CrossRef]

114. Russo, V.; Carbone, A.; Mottola, F.F.; Mocerino, R.; Verde, R.; Attena, E.; Verde, N.; Di Micco, P.; Nunziata, L.; Santelli, F.; et al. Effect of Triple Combination Therapy With Lopinavir-Ritonavir, Azithromycin, and Hydroxychloroquine on QT Interval and Arrhythmic Risk in Hospitalized COVID-19 Patients. Front. Pharmacol. 2020, 11, 1-6. [CrossRef]

115. De Leon, J. Evidence-based medicine versus personalized medicine: Are they enemies? J. Clin. Psychopharmacol. 2012, 32, 153-164. [CrossRef]

116. Shah, R.R.; Smith, R.L. Inflammation-induced phenoconversion of polymorphic drug metabolizing enzymes: Hypothesis with implications for personalized medicine. Drug Metab. Dispos. 2015, 43, 400-410. [CrossRef]

117. Clark, S.R.; Warren, N.S.; Kim, G.; Jankowiak, D.; Schubert, K.O.; Kisely, S.; Forrester, T.; Baune, B.T.; Siskind, D.J. Elevated clozapine levels associated with infection: A systematic review. Schizophr. Res. 2018, 192, 50-56. [CrossRef]

118. De Leon, J.; Diaz, F.J. Serious respiratory infections can increase clozapine levels and contribute to side effects: A case report. Prog. Neuro-Psychopharmacol. Biol. Psychiatry 2003, 27, 1059-1063. [CrossRef]

119. Hefner, G.; Falter, T.; Bruns, K.; Hiemke, C. Elevated risperidone serum concentrations during acute inflammation, two cases. Int. J. Psychiatry Med. 2015, 50, 335-344. [CrossRef]

120. Hefner, G.; Shams, M.E.E.; Unterecker, S.; Falter, T.; Hiemke, C. Inflammation and psychotropic drugs: The relationship between C-reactive protein and antipsychotic drug levels. Psychopharmacology 2016, 233, 1695-1705. [CrossRef]

121. Spina, E.; Hiemke, C.; De Leon, J. Assessing drug-drug interactions through therapeutic drug monitoring when administering oral second-generation antipsychotics. Expert Opin. Drug Metab. Toxicol. 2016, 12, 407-422. [CrossRef]

122. Moore, T.J.; Cohen, M.R.; Furberg, C.D. Serious adverse drug events reported to the Food and Drug Administration, 1998-2005. Arch. Intern. Med. 2007, 167, 1752-1759. [CrossRef] 
123. De Leon, J.; Sanz, E.J.; De Las Cuevas, C. Data from the World Health Organization's Pharmacovigilance Database Supports the Prominent Role of Pneumonia in Mortality Associated with Clozapine Adverse Drug Reactions. Schizophr. Bull. 2020, 46, 1-3. [CrossRef] [PubMed]

124. De Leon, J.; Sanz, E.J.; Norén, G.N.; De las Cuevas, C. Pneumonia may be more frequent and have more fatal outcomes with clozapine than with other second-generation antipsychotics. World Psychiatry 2020, 19, 120-121. [CrossRef] [PubMed]

125. Villasante-Tezanos, A.G.; Rohde, C.; Nielsen, J.; De Leon, J. Pneumonia risk: Approximately one-third is due to clozapine and two-thirds is due to treatment-resistant schizophrenia. Acta Psychiatr. Scand. 2020, 142, 66-67. [CrossRef] [PubMed]

126. Cicala, G.; Barbieri, M.A.; Spina, E.; De Leon, J. A comprehensive review of swallowing difficulties and dysphagia associated with antipsychotics in adults. Expert Rev. Clin. Pharmacol. 2019, 12, 219-234. [CrossRef] [PubMed]

127. Cranshaw, T.; Harikumar, T. COVID-19 Infection May Cause Clozapine Intoxication: Case Report and Discussion. Schizophr. Bull. 2020, 46, 751. [CrossRef] [PubMed]

Publisher's Note: MDPI stays neutral with regard to jurisdictional claims in published maps and institutional affiliations.

(C) 2020 by the authors. Licensee MDPI, Basel, Switzerland. This article is an open access article distributed under the terms and conditions of the Creative Commons Attribution (CC BY) license (http://creativecommons.org/licenses/by/4.0/). 